\title{
A 3D finite element model for predicting the fire behavior of hollow-core slabs
}

\author{
José V. Aguado $^{\mathrm{a}}$, V. Albero ${ }^{\mathrm{b}}$, A. Espinos ${ }^{\mathrm{b}}$, A. Hospitaler ${ }^{\mathrm{b}}$ and Manuel L. Romero ${ }^{\mathrm{b} *}$ \\ a Institut de Recherche en Génie Civil et Mécanique (GeM, CNRS) at École Centrale de \\ Nantes. 1 rue de la Noë, 44321 Nantes cedex 3, France. \\ ${ }^{\mathrm{b}}$ Instituto de Ciencia y Tecnología del Hormigón (ICITECH). Universitat Politècnica de \\ València, Spain.
}

\begin{abstract}
A nonlinear finite element three-dimensional model is presented and validated in this work against standard fire tests. The aim is to develop a numerical tool in order to study the behavior of prestressed Hollow Core (HC) slabs in the event of fire. A sequentially coupled approach is considered in order to perform the thermo-mechanical analysis at an affordable computational cost. The model includes the effect of prestress and a realistic constitutive inelastic behavior of concrete, for both tension and compression. It takes into account the temperature dependency of the material properties, and thus the crack patterns due to bending, shear, thermal cracking and longitudinal cracking are reproduced. The model is validated by comparing the simulation results with 11 real fire resistance tests on single elements, obtaining satisfactory results in terms of both failure mechanism and failure time. Finally, the suitability of using the simple calculation models existing in the European codes (Eurocode 2, EN 1168) for the verification of the $\mathrm{HC}$ resistance in fire situation is discussed. In particular, the numerical results are compared to the simple calculation model given in the EN 1168.
\end{abstract}

Keywords: fire resistance, hollow core slabs, finite element analysis

*Corresponding author: Tel: +34-963877007(ext:76742) Fax: +34-963879679,

E-mail address: mromero@mes.upv.es 


\section{NOTATION}

$\begin{array}{ll}A_{c} & \text { Cross-sectional area of concrete } \\ A_{p} & \text { Area of prestressing tendon or tendons } \\ b_{w} & \text { Web width } \\ d & \text { Effective depth of a cross-section } \\ \text { EC2 } & \text { Eurocode 2 Part 1-2 (EN 1992-1-2) } \\ f_{\mathrm{c}} & \text { Compressive strength of concrete } \\ f_{\mathrm{yk}} & \text { Characteristic yield strength of reinforcement } \\ \mathrm{HC} & \text { Hollow core } \\ \eta & \text { Load ratio } \\ \mu & \text { Friction coefficient } \\ \xi_{\mathrm{Vu}} & \text { Error ratio in terms of ultimate load } \\ \xi_{\mathrm{t}} & \text { Error ratio in terms of failure time }\end{array}$

\section{INTRODUCTION}

In the last decades, precast prestressed hollow core (HC) slabs have gradually increased their market presence in many countries due to their excellent structural performance at room temperature, advanced manufacturing methods, and low-cost installation. Nowadays, HC slabs have consolidated their position, providing an attractive choice for engineers when concrete or composite floor structures in buildings must be designed. There are many reasons for this success, but from an engineering point of view it is clear that prestressed reinforcement is one of the key aspects. Prestressing improves the serviceability performance of HC slabs compared to reinforced concrete slabs, increasing the cracking moment, although similar performance could also be attained using postensionning.

Simultaneously with the introduction of HC slabs, researchers have dedicated many efforts aiming to understand their structural behavior [1]. These efforts, including several experimental programs [2], [3], [4], which have led the scientific community to be able to develop calculation methods, constructional guides and design standards. Additionally, its behavior in floor systems 
has been analyzed [5], [6], [7]. As a consequence, today it is generally accepted that an accurate knowledge has been achieved relative to $\mathrm{HC}$ slabs behavior at room temperature.

On the contrary, experience has proved that there exists a lack of understanding concerning the fire behavior of HC slabs, specifically related to their numerical modelling. Van Overbeek et al. [8] analyzed some tests (32) that have been carried out in last years, and concluded that a disturbing quantity of $45 \%$ of them did not fulfill the expectations of the Dutch NEN6071 standard in terms of failure time under fire conditions.

Jansze, et al. [9] collected a database with 162 fire test results of HC slabs from 1966 until 2010, through "Holcofire" research project. This research work concludes that all 162 tests can be explained with the calculation rules from the standards, showing that do not give enough information about the effect of restrained and support conditions on the fire behavior of HC slabs, which need additional research. This research report analyzed aspects like flexible supports or horizontal web cracking, providing some recommendations in order to deal with these issues.

As a consequence, a certain lack of confidence in $\mathrm{HC}$ slabs has spread among engineers and designers related to their fire resistance. Therefore, it seems to be clear that some of the simplified verification procedures given by design standards such as Eurocode 2 Part 1-2 [10] neglect some variables that have an important influence on the final behavior of HC slabs.

In addition, experience shows that HC slabs exhibit a quite complex thermo-mechanical behavior. Four different types of failure have been identified: bending, shear tension, shear flexure and anchorage failure. But besides these principal mechanisms, other secondary phenomena have also been identified such as thermal or longitudinal cracking [11]. These phenomena are called secondary because they are not the principal cause of failure but they interact with the main failure mechanisms with a remarkable influence in the final behavior. 
Close to the previous variety of structural phenomena, degradation of material properties due to the temperature raise has to be considered. In addition, radiation occurs inside the cores (i.e. hollow cores), which significantly influences the temperature field, as well as the moisture content of concrete. Considering all together these phenomena leads to a complex, transient and strongly non-linear problem. In consequence, it may be concluded that numerical methods rather than analytical approaches are suitable for developing models for predicting the fire behavior of HC slabs. Moreover, the numerical model, once it has been validated, enables the execution of numerical tests instead of the expensive experimental programs.

Rather than investigating specific phenomena through particular models, this papers presents a comprehensive, general purpose numerical model which is able to reproduce the primary failure modes (bending and shear) as well as the secondary mechanisms (thermal and longitudinal cracking), that occur simultaneously and interact each other. The importance of taking into account the secondary mechanisms has been clearly pointed out in [9]. Although many important variables such as the influence of the axial restrain, the flexibility of the supports or the structural topping are not investigated in this paper for the sake of concretion, the numerical model would allow it. The main limitation of the numerical model capabilities is the anchorage failure, which cannot be currently predicted as it constitutes an ongoing work.

Results of the numerical model are validated against tests from authors as well as some other tests available in the literature. Besides a few design variables are analyzed through the numerical model and the simplified methods from the standards are discussed.

\section{NUMERICAL MODEL}

\subsection{Previous models review}

As a first step, some numerical models proposed by other authors to assess the HC slab behavior under fire conditions should be analyzed. 
Dotreppe and Franssen [12] investigated thermal cracking and the degree of restrain influence in the fire behavior of HC slabs. For this purpose, they developed a finite element heat transfer model. Radiation inside the void was taken into account, proving its significant influence. Thermal results were subsequently transferred to the mechanical model. From the results obtained through this model it was concluded that restraint has a favorable effect both in shear capacity, because thermal cracking is reduced, but also in bending capacity, because restraining induces a reversed moment that counteracts deflection.

Other finite element heat transfer model for HC slabs was developed by Venanzi, et al. [13] taking into account convection and radiation inside the holes. That model was satisfactorily validated with their own experimental results. Through these tests a premature collapse cause by spalling could be observed and a considerable reduction (around $50 \%$ ) of residual strength of $\mathrm{HC}$ after fire was evaluated. However these experiments were made using $\mathrm{HC}$ slabs produced with High Performance Lightweight Concrete (HPLWC) which is very unusual in the HC industry.

The main objective of Fellinger et al. [14] was to assess shear and anchorage behavior of HC slabs. Thermomechanical behaviour was studied in a separate way by means of a heat transfer model and a mechanical model, both using the finite element method. Thanks to an accurate modeling of tensile concrete behavior at high temperatures, model from Fellinger introduced two important novelties:

- Modeling of anchorage and shear tension was achieved obtaining a reasonable agreement between numerical results and test data.

- Both splitting and longitudinal cracking were successfully reproduced.

A thermo-mechanical model using the finite element method also was proposed by Shakya and Kodur [15] in order to study the effect of critical parameters such as fire scenario, load level, restrain conditions and aggregate type on the behavior of $\mathrm{HC}$ slabs under fire conditions. 
Like Dotreppe and Fransen [12] this model also concluded that axial restraint provides a significant benefit on the fire response of HC slabs. A higher fire resistance was observed when using carbonate aggregate as compared to siliceous aggregate.

In contrast to the previous authors, Chang et al. [16] decided to confront a more ambitious problem. They tried to reproduce the global behavior of a whole floor system composed of HC slabs. As an explicit modeling would have been numerically expensive, they built a simplified one based on a grid of beam elements. Concrete topping was also included by means of two dimensional shell elements. The model was able to capture the global behavior of the floor system as long as the shear influences were negligible.

From the analysis of the previous modeling attempts, it can be noticed that all of them share an important characteristic: thermal calculations are considered to be independent of the mechanical behavior. This is a sequentially coupled analysis, i.e. both heat transfer and mechanical analysis can be performed independently. In addition, some previous models are able to reproduce the $\mathrm{HC}$ slab behavior as shear and flexural failure, thermal craking, etc. but in an unrelated way. In contrast, the aim of this research is the development of a unique numerical model to reproduce all these features.

\subsection{Geometry and finite element mesh}

In contrast with some works of other authors, who built an equivalent $2 \mathrm{D}$ model of the $\mathrm{HC}$ slab [13], this work aims to be more realistic and therefore a 3D finite element model was created, using the general purpose nonlinear finite element analysis package ABAQUS. Only half of the slab was modelled because of the symmetry. With this purpose, 8-node linear hexahedra elements were used for meshing HC slabs. The prestressing strands were modeled as 2-node linear truss elements, 1D finite element, because of its small cross-section compared to the whole HC slab. 
First order (linear interpolation) elements were used for both thermal and mechanical problems. In order to avoid incompatible strains leading to spurious stresses [17], [18], thermal strains are approximated one order lower than temperature [19]. A mesh of $2 \mathrm{~cm}$ was prescribed as in previous works from the authors [20]. This mesh can be seen in Figure 1. The mesh quality factor for hexahedra elements were an angle on quad faces range from 25 to 160 (average minimum angle: 73.41; average maximum angle: 106.36) and 1.86 of average aspect ratio (worst aspect ratio: 5.08). Strand was meshed with $1 \mathrm{~cm}$ element size. It should be noticed that the computational cost due to reinforcement is totally negligible compared to that required for analyzing the rest of the slab, and therefore its mesh was a little bit finer in order to ensure the quality of results. Truss elements are constrained to follow the response of the surrounding solid elements by defining an "Embedded element constraint".

Besides, as can be seen in Figure 1, when loading and support conditions were symmetric relative to longitudinal or transverse axes, only a half or a quarter of the $\mathrm{HC}$ slab needed to be modeled.

\subsection{Material properties}

Following the recommendations in Eurocode 2 (EC2) [10], which suggests that the influence of reinforcement on the temperature field can be neglected, only the thermal behavior of concrete was taken into account.

From a previous experimental program performed by the same authors [11], concrete compressive and tensile strength, steel tensile strength, steel elastic modulus, concrete moisture content and aggregate type were obtained. Knowing these set of properties, a complete constitutive model for the materials is built in the following sections. 


\subsubsection{Thermal behavior of concrete}

Density, conductivity and specific heat are the three material properties that influence the heat transfer problem. All of them were considered to be dependent on the temperature, and EC2 values were applied [10]. In addition, EC2 accepts to take into account the energy consumption for vaporizing the moisture content of concrete as a peak in the specific heat between $100^{\circ}$ and $200^{\circ} \mathrm{C}$. This is neither the only alternative nor the most accurate one, as enthalpy might be used instead of specific heat in the heat equation, or even a full hygrothermal model might be solved. The magnitude of this specific heat peak defined by EC2 depends on the weight percentage of humidity. It is well-known that moisture vaporization leads temperature to be stabilized around $100^{\circ} \mathrm{C}$ while water content is consumed, which is commonly known as the temperature plateau. However, it was found that using a peak such as the one proposed by the EC2 gave systematically place to a rather unrealistic plateau, meaning that this plateau was not straight but significantly sloped instead (Figure 2b). For this reason, it was decided to modify the specific heat peak in order to improve results (Figure 2a). Considering that the area under the specific heat versus temperature curve represents energy, it was proposed to build a new peak containing the same area than the original one (i.e. the same dissipated energy) but reducing its temperature range of definition. Therefore, as the basis of the peak was reduced and the area did not change, the peak value increased. While the peak originally proposed by EC2 ranged from 100 to $200^{\circ} \mathrm{C}$, the new one ranged from 100 to $120^{\circ} \mathrm{C}$. In doing so, the new peak value could be calculated. Proceeding this way, a more realistic plateau was achieved (Figure 2b,c), or equivalently, moisture influence was simulated more accurately.

However, it must be pointed out that creating this peak in the specific heat leads to some convergence difficulties. This is not a surprise, because the sharper the peak, smaller the time increments have to be in order to follow accurately the peak avoiding divergence. 


\subsubsection{Multi-axial mechanical behavior of concrete}

Because a three-dimensional finite element analysis of $\mathrm{HC}$ slabs is carried out, multi-axial behavior of concrete must be defined. ABAQUS includes several material models, among which Concrete Damaged Plasticity (CDP) allows capturing both fundamental types of failure of concrete: crushing and cracking. Details can be found in the following reference [19]. The tridimensional behavior is built from the uniaxial behavior of concrete (see Section 2.3.3) and some other parameters that are obtained from other previous works of the authors [21]. The parameters used for this model are the following: dilation angle of $15^{\circ}$, eccentricity of 0.1 , initial equibiaxial to initial uniaxial compressive yield stress ratio of 1.16 and the parameter related to the shape of the yield surface in the deviatoric plane equal to $2 / 3$. No variation of these parameters in terms of temperature was considered. Finally, damage parameters governing changes in the constitutive behavior due to a cyclic loading were included because even if the load is monotonic, some regions change from tension to compression (or vice versa) due to thermal effects. The damage variables, one for tension and other for compression, can take values from zero, representing the undamaged material, to one, which represents total loss of strength. Values for these damage parameters for both tension and compression are taken from Cicekli et al. [22].

\subsubsection{Uniaxial mechanical behavior of concrete at high temperatures}

Concrete exhibits strongly different behavior depending on whether compressive or tensile stresses apply. When HC slabs are subjected to bending, tensile stresses become more relevant than compressive ones and the stresses are transferred from cracked concrete to reinforcing steel. Tensile stresses also control the failure mechanism in case of shear loading, and they are responsible of thermal cracking and many other degradation processes of concrete. All these phenomena occur despite the initial compressive state conferred to the HC slab by prestressing. 
For this reason, this work pays more attention to concrete modeling under tensile loading rather than under compression. Strain of concrete at high temperatures can be thought as the sum of four components, each of them representing different physical phenomenon [23]:

$$
\varepsilon=\varepsilon_{t h}+\varepsilon_{m}+\varepsilon_{c r}+\varepsilon_{t r}
$$

where $\varepsilon_{t h}, \varepsilon_{m}, \varepsilon_{c r}$ and $\varepsilon_{t r}$ are thermal, mechanical, creep and transient creep strains, respectively. Creep strains, however, can be neglected due to the fact that time associated to fire testing is about minutes or hours while creep strains become significant for longer periods of time.

Thermal strains are assumed to be isotropic and dependent on the type of aggregate (silicious or calcareous), the relation proposed by EC2 is selected. When concrete is composed of a mixture of aggregates, a linear interpolation is made depending on the percentage of each aggregate type.

\section{Compressive behavior}

EC2 suggests a uniaxial stress-strain relation for concrete under compressive loading at high temperatures which includes implicitly both mechanical and transient creep strains. This model has been chosen due to its simplicity provided that the influence of compressive behavior in the final response of HC slabs under flexural loading is not as decisive as it is for concrete filled tubular columns [20]. Beyond the maximum stress, a linear descending branch is assumed for compressive EC2 stress-strain relation.

\section{$\underline{\text { Tensile behavior }}$}

Related with tension behavior of concrete, it is a quite classical assumption to consider concrete to behave as linear elastic up to its cracking stress. Beyond this point, concrete exhibits a brittle behavior and cracking takes place. Due to numerical convenience, cracking was better 
described in terms of stress versus crack opening relations. Fracture energy is closely linked to these relations as it represents the area under the stress-crack opening curve. Different models were tested (bi-linear from Model Code [24], Fellinger [25]), but the one found to give the best results in terms of modeling consistency and numerical convergence was that originally suggested by Gopalaratnam and Shah [26], and used by other authors as Nielsen and Bicanic [27], Hegger et al. [28] (Figure 3):

$$
\sigma_{t}=f_{c t} \cdot \exp \left(-\frac{w \cdot f_{c t}}{G_{F}}\right)
$$

where:

$\sigma_{t}$ is the tensile stress retained at a given crack opening, $w$.

$f_{c t}$ is the tensile cracking strength.

$G_{F}$ is the tensile fracture energy.

Notice that if temperature dependence of both cracking stress and fracture energy are known, the model is completely defined. Many authors have investigated how cracking strength evolves with temperature. For instance, Fellinger [25] provides a comparison of different works from which it can be concluded that results are strongly scattered. When comparing the evolution given by EC2 with the previous ones, it can be observed that EC2 proposal seems to be a sort of averaging. Given the uncertainty on this matter and the lack of evidences in favor of any model, the authors chose the EC2 proposal.

Regarding fracture energy, it can be calculated at room temperature following Model Code [24]:

$$
G_{F}=73 \cdot f_{c}^{0.18}
$$

Model Code [24] gives the temperature effect for increments up to $80^{\circ} \mathrm{C}$, which is clearly insufficient for the purposes of this work. Other works on this matter have been studied by 
Bazant-Zdenek [29] and Nielsen-Bicanic [27], finding a low increment on fracture energy up to $400^{\circ} \mathrm{C}$ and a final reduction beyond this temperature, however most of these observations are qualitative rather than quantitative. As a choice must be done, following these investigations and on the safe side, the authors propose using the Model Code [24] value up to $400{ }^{\circ} \mathrm{C}$ and a subsequent decrease following the evolution of cracking stress provided by EC2 ( $k_{c, t}$ from section 3.2.2.2 of EC2 Part 1-2).

$$
G_{F, \theta}= \begin{cases}G_{F} & \theta \leq 400^{\circ} C \\ k_{c, t}(\theta) \cdot G_{F} & \theta>400^{\circ} C\end{cases}
$$

\subsubsection{Uniaxial behavior of steel at high temperatures}

Steel behavior is assumed to be mainly explained in terms of only two kinds of strains: thermal and mechanical strain. Relaxation of steel starting from manufacturing until HC slab testing is taken into account as a part of the total loss of stress (see section 2.4). Therefore, stress-strain curves are taken from EC2, as well as thermal expansion of steel. It is worth reminding that as steel reinforcement is modeled by means of $1 \mathrm{D}$ truss elements (which can only carry uniaxial stresses) there is no need of defining a multi-axial behavior.

\subsection{Numerical modelling of prestress}

Reinforcement was considered to be perfectly bonded to concrete, which is a generally accepted simplification because modeling a realistic contact between steel and concrete increases dramatically the computational cost of the model. When assuming perfect bond, it is evident that the transmission length cannot be simulated in a natural way, and consequently an alternative technique was needed. Hegger et al. [28] proposed a quite simple procedure which has been followed in this work. This procedure consists in:

- Firstly calculating the transfer length following EC2. 
- Secondly estimating the final prestressing stress by taking into account the different stress loses (shrinkage, creep, relaxation, etc.)

- And thirdly assuming a shape function (typically, linear or parabolic) for the evolution of the stress from the free end to the end of the transmission length (Figure $4)$.

The stress is equal to zero at the free end of the $\mathrm{HC}$ slab, reaching the final stress value at a length equal to the transmission length. In this research, losses of stress were estimated, because the complete history of each HC slab was not available. A prudent value of $30 \%$ was assumed in this work. In addition, it was also assumed that stress varies linearly from the free end up to the transmission length.

\subsection{Analysis procedure}

As the thermo-mechanical behavior is of interest, the analysis may be performed in two different manners: fully coupled and sequentially coupled approaches. The first approach is to consider a fully coupled thermo-mechanical problem, which implies to solve simultaneously both thermal and mechanical unknowns of the FE model. This is a general but computationally expensive procedure. The alternative consists in solving the heat transfer problem independently and afterwards imposing the temperature field into the mechanical model, as in previous works from the authors of this paper [20].

This last option, a sequentially coupled approach, was chosen due to its computational competitiveness. In addition, it is worth remarking that most of authors have also chosen this analysis procedure, [14], [15].

In summary, Figure 5 shows the general scheme of the followed analysis procedure. As can be seen, the model is composed of two sub-models, the thermal and the mechanical one. Indeed 
the mechanical model needs the prestressing sub-model, which was explained before, and whose mission is to introduce the initial stress state into the reinforcing wires or strands.

Taking into account all previously described models and sub-models, and following Figure 5 , the mechanical model runs as follows.

- In first place, the initial stress state is imported from the prestressing sub-model. As the reinforcement is perfectly bonded to the concrete, the prestressing force is transmitted to the HC slab and as a result concrete acquires a precompression. This procedure can be seen as a condensation of the $\mathrm{HC}$ slab industrial manufacturing process, provided that until this point the only task that has been done is to set the HC slab model into similar conditions with respect to the real HC slab. However, it is well-known that some time-dependent phenomena take place, like for instance relaxation of steel. This means that the initial stress state due to prestressing depends on the HC slab age, among other parameters, which in general are difficult to control. Therefore the loss of prestress had to be estimated, as explained in the precedent section. In doing so, it is considered that at the end of the prestressing stage, the HC slab model is representative of the real stress state of the HC slab.

- The second step consists in applying the same load, a percentage of the maximum load capacity at room temperature, which was applied in the tests, in order to be able to validate numerical results. In general, this load is maintained during the test.

- Thirdly, the temperature field is imported from the thermal model. This is a timedependent field which induces thermal strains and degradation of material properties among other phenomena. The calculation is stopped when the $\mathrm{HC}$ is so damaged that convergence cannot be achieved. 


\subsection{Thermal analysis}

A three-dimensional model was developed in order to simulate the heat transfer problem. On the contrary to previous works that preferred two-dimensional models, the model proposed in this paper is able not only to reproduce the general thermal behavior but also to capture the border effects and their influence in the mechanical behavior. In addition, if the same mesh topology is used for both thermal and mechanical problems, the temperature field can be easily transferred from the thermal to the mechanical problem so that interpolation errors due to mapping between dissimilar meshes are avoided.

Testing facilities allowed achieving a uniform fire exposure, that is to say the gas temperature did not vary significantly over the exposed surface. The standard fire curve ISO834 was almost perfectly followed in all validation cases.

As HC slabs were heated from below and their lateral sides were insulated, the only exposed surface was considered to be the HC slab bottom surface. Other four types of boundaries can be identified (Figure 6):

- Insulated surfaces. Those covered with insulation panels in such a way that no appreciable gain or loss of heat was produced through themselves.

- Symmetry surfaces. This type of boundary allows reducing the model size without losing accuracy. As in the previous case, a zero flux boundary condition is prescribed (adiabatic).

- Unexposed surfaces. Those exposed to room conditions, and in consequence, subjected to convective and radiative heat exchanges.

- Hollow core surfaces. Due to the presence of voids, it seems to be clear that radiation flux is established between the lower (hotter) area and the upper (colder) area of the void. Radiation is modelled through the average-temperature radiation capability of ABAQUS [19]. It constitutes and approximation of the radiative problem inside the 
hollow core, as heat flux is established between the hollow core surfaces and an average temperature of the hollow core. Therefore, the view factors computation is avoided. However, air inside voids was not allowed to be renewed and therefore its temperature is expected to rise up as the test develops. This assumption implies that a convective heat exchange will also occur inside the void. However, it must be noticed that the evolution of air temperature inside the voids is completely unknown. Some authors have suggested to consider that the air temperature is uniform inside the void, i.e. there is no stratification, and that it follows the average temperature of the void surfaces. Equation (5) reflects this assumption. This estimation is based on the fact that the specific heat of air is much lower than that of concrete.

$$
T_{a}=\frac{1}{S} \oint T d S
$$

Coefficient of heat transfer by convection (film coefficient) as well as concrete emissivity are taken from Eurocode 1 Part 1.2 [30]. In particular, the film coefficient is taken equal to 25 $\mathrm{W} / \mathrm{m}^{2} / \mathrm{K}$ on the exposed surface. On the unexposed surfaces a film coefficient of $4 \mathrm{~W} / \mathrm{m}^{2} / \mathrm{K}$ has been considered. Regarding the hollow core surfaces, there is a lack of knowledge on the proper value of the film coefficient. A value of $25 \mathrm{~W} / \mathrm{m}^{2} / \mathrm{K}$ was found to give the best results. On the other hand, a concrete emissivity of 0.8 was considered whereas shape factors are automatically computed by ABAQUS for the different faces that constitute the hollow core.

As it was said before, the problem to be solved is transient and non-linear, meaning that a linearization procedure is mandatory where a Newton-Raphson linearization was used. A timeintegration scheme is required as well and the backward difference algorithm was applied, leading to an implicit system which is, from a theoretical point of view, unconditionally stable. 


\subsection{Mechanical analysis}

\subsubsection{Support conditions and loading}

Support and loading conditions are created aiming to reflect real conditions during tests. Usually single $\mathrm{HC}$ slabs bears on a metallic frame and therefore slabs could slip over it and rotate. A contact interaction needs to be defined in order to allow such a behavior. This contact interaction is defined by the normal and tangent behavior. Normal behavior is defined in such a way that support penetration into the $\mathrm{HC}$ slab is not allowed. Enforcing this requirement strictly implies using Lagrange multipliers, which was found to induce some convergence difficulties and increased numerical cost. For this reason, a penalty method was applied instead. This method avoids Lagrange multipliers by using contact stiffness, so that numerical difficulties were relaxed. When the HC slab tries to become separated from the support, there is no force counter-acting this movement. This means that pressure from the HC slab to the support can only be transferred if clearance between both of them is zero.

Regarding the tangential contact behavior, it is defined using a Coulomb friction model. This kind of model defines a critical shear stress as a fraction of the contact pressure between the surfaces. This fraction is the friction coefficient, $\mu$, which is chosen equal to 0.3 after a sensibility analysis carried out. When shear stress exceeds the critical value at a given node, this node starts slipping and therefore a series of iterations are needed to reach convergence.

In the numerical model developed, the load was applied through a rigid plate. It was chosen to be rigid because the loading device stiffness in the tests was much greater compared to that of the HC slab. In addition, the plate was allowed to move only in vertical direction. However, the HC slab should be allowed to slip and to become separated from the plate as well. For this reason, a contact interaction between the loading plate and the $\mathrm{HC}$ slab was defined in the same terms as stated before regarding the support condition. 
In some cases, when loading and support conditions were symmetric relative to longitudinal or transverse axes, only a half or a quarter of the HC slab needed to be modeled. In consequence, a half or a quarter of the test load was applied.

\subsubsection{Resolution process}

The multiple sources of non-linearity that take place within the mechanical model require defining how they are treated in order to achieve a solution. Non-linearity comes from material behavior (inelasticity), geometric non-linearity (great displacements) and contact interactions.

A quasi-static analysis was performed, meaning that inertia effects are neglected. Loading was kept constant during the analysis, and therefore the thermal loading is the only action which varies during the time. However, it must be clarified that time was not a true variable since inertia forces were neglected and constitutive equations are not time-dependent. In consequence, there is no need of a time integration scheme. On the contrary linearization is compulsory, and the Newton-Raphson algorithm was applied.

\section{VALIDATION OF THE NUMERICAL MODEL}

Throughout this section, both thermal and mechanical models are validated using a previous experimental program from the same authors [11] and test results from literature. It is important to remark the difficulty of using test results from other authors because of the heterogeneity of test configurations.

\subsection{Mechanical response at room temperature}

The first step was the validation of the numerical model described previously through experimental tests at room temperature from bibliography. Specifically tests from Fellinger and Hegger were used [25], [5]. The geometric characteristics of these specimens are shown in Table 1. 
All of these tests were carried out with the load placed eccentrically respect to the mid-span, similar to the standard shear test loading scheme. Deeper details about test conditions and results are presented in references [25] and [5]. Cross-section shape of these specimens are displayed in Figure 7.

Two different failure mechanisms can be distinguished. Most specimens showed shear tension failure mechanism although two of these tests collapsed through flexural failure. This fact is useful to check the goodness of the FE model in different failure scenarios.

The main result observed is the maximum load capacity. FE model presents an accurate prediction, under shear and flexural failure mechanisms, in all specimens with an average error of 1.00 and standard deviation of 0.05 , see Table 2 and Figure 8.

\subsection{Thermal response}

After the validation of the numerical model at room temperature, the next step, in a sequential process, was the thermal sub-model validation. The cross section shape of the specimens used for both thermal and mechanical validation at high temperature are displayed in Figure 9, also Table 3a and 3b show their geometry.

Specifically, the validation of thermal sub-model was carried out through test from Aguado et al. [11] and Fellinger [25]. Temperature profiles along cross-section were registered for three different slabs from Fellinger (A200, HV260, K400) and one from Aguado (HC25-A2). Figure 10 compares test and FE results at different fire exposure times $(30,60,90)$, it should be noted that not all specimens were validated at same fire exposure time because of their different failure times. In test from Fellinger, despite measured temperatures were only available up to $0.20 \mathrm{~m}$ away from the exposed surface (where thermocouples were experimentally placed), numerical prediction was depicted along the entire cross section. 
In all cases shown in Figure 10, a good correlation was achieved between test and numerical results, therefore the thermal model can be considered successfully validated.

\subsection{Mechanical response at high temperature}

The last step in this validation process and the main target of this work is the validation of the mechanical model at high temperature. Some of the specimens shown in Figure 9 and detailed in Table $3 \mathrm{a}$ and $3 \mathrm{~b}$ were used to achieve this aim, specifically slabs HC25-A1, HC25A2, HC25-A3 and HC25-A4 from Aguado et al. [11] test; slab SP22 from tests from Andersen and Lauridsen [31] and finally specimens X200, VX265 and XB200 from test from Fellinger [25].

Using this slab collection, the numerical model was validated under three different test scenarios. The first one corresponds to test from Aguado et al. [11], which enables the numerical model to be checked under flexural behavior and moderate load ratios. The second scenario was conceived by Andersen [31] tests, which used a four-point test setup (flexure test) but with high load ratios, leading to shear failure near the supports. These scenarios fit with flexural tests configuration shown in Figure 11a. Finally, the third scenario was taken from Fellinger [25] as a shear test (Figure 11b), discarding those slabs which exhibited anchorage failure because the numerical model is unable to reproduce this type of failure. This last scenario allows validating the numerical model against shear loading (i.e. load applied at 2.5 times the height of the slab from the support).

Therefore, the numerical model was able to predict flexural failure when a four-point test setup was used (first scenario), but also predicted shear failure in the same test conditions (second scenario). Furthermore, when a shear test configuration was considered, the model was still able to predict shear failure (third scenario, VX265 slab) and flexural failure as well (third scenario, X200 and XB200 slabs). This means that regardless of the test configuration, the slab 
geometry or the load level, the numerical model was able to predict the failure mechanism giving good predictions.

Figure 12 and Table 4 show quantitative results of this validation, analyzing all scenarios together. An accurate prediction in terms of failure time can be observed, with 1.10 average error, which lies on the safe side, and 0.08 standard deviation.

However, the numerical moldel's prediction for specimen HC25-A3 is not satisfactory, since a $22 \%$ error (19 minutes) was observed. Although further research is needed, a possible explanation is given here. As discussed in [11], strands tend to produce splitting (radial cracking around the reinforcement), while wires do not. It was observed that moisture migrated from concrete to the channels created by splitting around the strand. It condensed and flowed through these channels, creating a thermal gap between concrete and steel. This conjecture, if demonstrated, would compromise the widely accepted hypothesis which states the concretesteel thermal compatibility.

Observe that specimen HC25-A3 is the only one with strands placed in the second row, see Table 3b. In that position, the concrete cover is minimum which favors the splitting cracking, which occurred in fact. An hygrothermal modelling, which is outside of the scope of this work, would be needed to reproduce the described phenomenon.

In the next sections, the results achieved in each test scenario will be developed and explained.

\subsubsection{First scenario: four point setup and moderate load ratio}

Details of these tests can be found in [11], which a moderate load ratio (36\%) is used. Figure 13 compares mid-span deflection measured for HC25-A2 slab and the calculated one, showing a good fitting. The numerical model is able to capture the flexural failure mechanism. Thermal stresses lead to web cracking during the first 20-30 minutes of fire exposure. After that, 
deflection rate is stabilized until reinforcement yields leading to final failure. The numerical results do not fit the experimental measures during the final stage due to convergence difficulties found. The reasons for this inability must be further investigated. However, the influence of this issue is limited because the final stage develops quite rapidly, and therefore the model is still able to produce reasonably good predictions in terms of failure time, as explained in section 3.3 .

In the tests from Aguado et al. [11], the different crack patterns observed were described. In particular, flexural cracking, thermal cracking, longitudinal cracking and splitting were reported. Figure 14 shows that the numerical model is capable to reproduce all types of cracking except splitting, since perfect bond between concrete and steel was considered. In order to show crack patterns in the numerical model, the variable PEEQT (Equivalent plastic strain in uniaxial tension) is plotted. Specifically, Figure 14a depicts longitudinal cracking which splits the HC slab into individual ribs, occurring through the thinnest cross-section, which is located at both the bottom and top part of the core. Figure $14 \mathrm{~b}$ shows how the flexural cracks grow up from the bottom to the top. In addition, these cracks merge with thermal cracks which grow up through the webs during the first stage of fire exposure. It can be also seen that these cracks are perfectly vertical in the central zone. Finally, Figure 14c shows the HC slab from its bottom surface, where the flexural cracks can be observed in the central zone, distributed in a uniform pattern since the moment applied is constant through the central zone.

Figure 15 shows another prove of the numerical model capability to reproduce thermal cracks. Longitudinal stresses along web height are shown from their initial state until certain fire exposure times. The initial linear stress field due to prestress and load can be observed as well as its transformation during fire to tension in the central zone and compression on top and bottom flanges. This tension in the central zone is the cause of the thermal vertical cracks. 
Another additional view of flexural failure under fire through the numerical model is shown in Figure 16, where stress and temperature in different tendons are plotted. Through this figure an explanation of their behavior can be achieved. As tendons reach the thermal plateau, they start to relieve stresses. Besides, it can be observed that as those tendons which are more exposed to fire relieve their stresses, the more protected ones increase their stress level in order to supply enough strength to the section to counter-act the load. However, this mechanism works only up to the point where the next tendon also reaches its temperature plateau and starts to relieve its stress.

\subsubsection{Second scenario: four point setup and high load ratio}

In order to check the validity of the numerical model in different load conditions, SP-22 slab test from Andersen [31] was considered. A load ratio of 100\% was reported by Andersen [31]. Loading was arranged in order to reach both bending and shear ratios simultaneously, although this load represents a $90 \%$ of the shear capacity according to EN1168 Annex G. Even though a four point flexural test arrangement was used, this slab failed due to shear. This occurred because of the infrequent high load ratio applied. The numerical model is capable to reproduce this situation, achieving a good correspondence between both calculated and measured midspan deflections (Figure 17).

\subsubsection{Third scenario: shear test}

In this third scenario, the loading conditions are varied by moving from a four point test arrangement to a shear test conditions, where the load is placed eccentrically at 2.5 times the slab height from the support axis (Figure 11b). The test results were taken from Fellinger [25], in this case double rib specimens were used (cut from the entire $\mathrm{HC}$ slab) thus the numerical model comprised such geometry. 
On the one hand X200 and XB200 specimens showed a flexural failure, see Table 4. These experiments were carried out in a different way from a standard experimental test process. Both specimens reached 120 minutes fire endurance without collapse, so at that moment the load was increased gradually up to failure. In these cases, comparison should not be made between test and numerical model in terms of failure time because it was fixed, however a good fitting in ultimate load value can be observed.

On the other hand, specimen VX265 showed a shear failure (Figure 18). This experiment was performed in the standard way and a suitable value of failure time was achieved.

\subsection{Qualitative validation of crack patterns}

The numerical model presented in this paper enables to get insight in the understanding of the thermo-mechanical behavior of $\mathrm{HC}$ slabs at high temperatures. In particular, a correlation is established between the cracking patterns and the failure mechanism under both flexural and shear loading.

\subsubsection{Flexural failure}

In test from Aguado et al. [11], three different stages were identified by means of the deflection rate recorded during the tests (Figure 13). The first stage comprised around 20 minutes from the beginning of the fire testing. During this period, a remarkably high deflection rate was observed. The numerical model enables drawing an explanation based on the thermal cracking developed through the webs, confirming the assumption done in [11].

Once the web is fully cracked, the loss of stiffness is moderated and the second stage begins. Both moisture vaporization and progressive softening of the standard fire curve ISO834 contributed to delaying the rise in temperature, and thus deflection mainly took place because of the progressive degradation of material properties. 
The second stage concluded when most of the steel reinforcement lost its strength (Figure 16) and the deflection rate increased quickly. Afterwards, during the third stage, the HC slab fully lost its load-bearing capacity and a high deflection rate was observed up until the test was finished.

\subsubsection{Shear failure}

Shear failure is essentially a brittle failure, even at high temperatures. The numerical model enables drawing an explanation which agrees with work of Borgogno and Fontana [32] as thermal cracking developed through the web (Figure 15) interacts with shear stresses and is favorable to failure. This type of crack pattern can be observed in Figure 18.

\section{INFLUENCE OF DESIGN VARIABLES}

Once demonstrated the validity of the numerical model and its accurate behavior, a numerical analysis was carried out in order to know the influence of some key parameters in the mechanical response. Specifically, the type of aggregate and concrete strength were evaluated.

\subsection{Aggregate type}

The aggregate type has influence in the thermal expansion of concrete, in its strength evolution at high temperature and in the temperature development of the cross-section, through its conductivity. This influence comes from concrete material model suggested by EC2. Siliceous and calcareous aggregates can be distinguished but also a mixture can be used.

Three HC slab numerical models were developed with the aggregate type being the only difference between them. The mechanical response of the different models is shown in Figure 19. 
These results show the high influence of the aggregate type in the mechanical response of HC slabs at high temperatures. A mixture containing only siliceous aggregates exhibits a greater loss of stiffness and a higher deflection because of its higher thermal expansion and lower strength at high temperatures, which results in a faster thermal cracking. On the contrary a mixture containing only calcareous aggregates shows a smaller loss of stiffness and lower deflection. These conclusions agree with results from Shakya and Kodur [15].

Moreover, a mixture containing 50\% calcareous and 50\% siliceous shows an intermediate behavior. Therefore, a gradual response can be assumed between $100 \%$ calcareous and $100 \%$ siliceous depending on the percentage of each aggregate type in the mixture.

\subsection{Concrete strength}

Other evaluation of a design variable was carried out with concrete strength. Like in the previous assessment, the rest of variables were fixed, being the concrete strength the only difference between them.

Three numerical models were developed with a concrete cylinder strength of $57.2-50-40$ MPa using a $100 \%$ calcareous aggregate mixture in all of them. The mechanical response (midspan deflection) of these models is shown in Figure 20.

It can be observed that the mechanical response with these three values of concrete strength is very similar. It is important to point out that these numerical simulations were conducted up to flexural failure considering a four point test setup. Therefore, the similar behavior in all specimens despite their different concrete strength can be explained because of the tensile capacity of the tendons is the main mechanism against flexural failure. Thus, the only difference in their behavior is the compression area which is located in the unexposed side and not affected by thermal degradation. 


\section{COMPARISON WITH SIMPLIFIED DESIGN METHODS}

In this section, the numerical model is used to study and discuss the provisions in EC2 [10] and EN1168 [33] simple calculation method. Specifically, EC2 annex B.1 gives the $500^{\circ} \mathrm{C}$ isotherm simplified method to calculate the ultimate bending moment for a specific time of fire exposure. This method reduces the HC slab cross-section by excluding any concrete at a temperature over $500{ }^{\circ} \mathrm{C}$, preserving concrete mechanical properties at room temperature while it is below $500{ }^{\circ} \mathrm{C}$. In this method, the mechanical properties of steel reinforcement are decreased according to the individual temperature of each wire or strand using EC2 section 4.2.4.3 reduction factors.

Therefore, $500{ }^{\circ} \mathrm{C}$ isotherm simplified method requires a previous analysis of the crosssectional temperature field of the slab, exposed from its bottom surface to a standard fire, in order to establish each tendon temperature and the concrete cross-section portion which lies below $500{ }^{\circ} \mathrm{C}$. EN 1168 annex G.1.2 provides specific hypothesis to establish this temperature field as a uniaxial profile in HC slabs. In this standard, the a50\% level is defined, where the total web width is equal to the total core width. Below this level, the temperature profile can be assumed as that in concrete slabs provided by EC2 figure A.2. Otherwise, over a50\% level, a linear profile can be assumed with top surface $160^{\circ} \mathrm{C}$ hypothesis.

In this research, a finite element model was developed and calibrated, which can reproduce both bending and shear failure under fire exposure. Thus, this numerical model can be also used to assess EN 1168 Annex G.1.3 design method to calculate shear fire resistance of HC slabs, which provides the next formula:

$$
V_{R d, c, f i}=\left[C_{\theta .1}+\alpha_{k} \cdot C_{\theta .2}\right] \cdot b_{w} \cdot d
$$

where:

$C_{\theta .1}$ is the coefficient accounting for concrete stress under fire conditions: 


$$
\begin{gathered}
=0.15 \cdot \min \left(k_{p}\left(\theta_{p}\right) \cdot \sigma_{c p, 20^{\circ} C} ; \frac{F_{R, a, f i, p}}{A_{c}}\right) \\
\alpha_{k}=1+\sqrt{\frac{200}{d}} \leq 2.0 \text { with } \mathrm{d} \text { in } \mathrm{mm}
\end{gathered}
$$

$C_{\theta .2}$ is the coefficient accounting for anchored longitudinal reinforcement:

$$
=\sqrt[3]{0.58 \cdot \frac{F_{R, a, f i}}{f_{y k} \cdot b_{w} \cdot d} \cdot f_{c, f i, m}}
$$

The variables needed to evaluate the last formula $\left(F_{R, a, f i, p}, F_{R, a, f i}, f_{c, f i, m}\right.$, etc.) can be obtained from EN 1168 [33].

The comparison between numerical and simplified method results are shown in Table 4 and Figure 21. The same specimens used before to validate numerical model at high temperatures were analyzed. Through the previously explained simplified methods to assess the failure time under bending and shear failure, the expected failure mode can be predicted. When the $500^{\circ} \mathrm{C}$ isotherm method provides a lower failure time than EN 1168 shear model at high temperatures, flexural failure can be expected. On the contrary, when EN 1168 shear model at high temperature provides a lower failure time than the $500^{\circ} \mathrm{C}$ isotherm method, a shear failure can be expected.

In the tests from Aguado et al. [11] and Andersen and Lauridsen [31], the simplified methods predict correctly a flexural failure mode that occurs in both numerical model and experimental test, however the failure time is not always predicted on the safe side with an average error of 0.93 and standard deviation of 0.30 , see Table 4. In turn, regarding to tests from Fellinger [25], which were carried out under shear loading conditions, the simplified method prediction of failure mode is correct in VX265 slab which shows a shear failure mode around 30 minutes with EN 1168 shear model. Also it is interesting to observe that the simplified methods do not predict shear failure in XB200 specimen before 120 minutes. This prediction matches with 
experimental and numerical observation for this specimen, where failure did not occur before 120 minutes of fire exposure and the slab was further loaded up to failure. However, specimen X200 showed the same experimental and numerical behavior than XB200 but the simplified method predicted a premature shear failure at 75 minutes that did not occur.

In all, although the limited number of tests available for comparison do not make it possible to establish solid conclusions, it can be observed that the simplified method predictions leads to scattered results. A deeper analysis should be carried out in order to generalize these findings.

\section{CONCLUSIONS}

In this work, an advanced numerical model for predicting the thermo-mechanical behavior of HC slabs was presented and deeply described. This numerical model considered the full 3D slab geometry and included realistic material behavior (inelastic behavior both in tension and compression). The numerical model was successfully validated under different failure scenarios and, as a consequence, it was able to predict the failure mode (bending or shear) as well as thermal, flexural and longitudinal cracking. The internal behavior of thermal cracking was fully understood through the model developed and, the influence of some design variables was studied, observing a better fire behavior of calcareous aggregate concrete. Besides, no significant differences were observed when using different concrete strengths. Finally, after an evaluation of the current code provisions, it was found that the simplified method predictions leads to scattered results, therefore a deeper analysis should be carried out.

\section{REFERENCES}

[1] J.C. Walraven, W.P.M. Mercx, The bearing capacity of prestressed hollowcore slabs, Heron. 28(1983)1-46.

[2] R.J. Becker, D.R. Buettner, Shear tests of extruded hollow core slabs, PCI Journal. 30(1985) 40-54. 
[3] M. Pajari, H. Koukkari, Shear resistance of PHC slabs supported on beams. I: Tests, Journal of Structural Engineering. 9(1998) 1050-1061.

[4] A. Pisanty, The shear strength of extruded hollow-core slabs, Materials and Structures. 25(1992) 224-230.

[5] J. Hegger, T. Roggendorf, N. Kerkeni, Shear capacity of prestressed hollow core slabs in slim floor constructions, Engineering Structures. 31(2009) 551-559.

[6] D. Lam, K.S. Elliott, D.A. Nethercot, Parametric study on composite steel beams with precast concrete hollow core floor slabs, Journal of Constructional Steel Research. 54(2000) 283-304.

[7] J.Y. Song, K.S. Elliott, H. Lee, H.G. Kwak, Load distribution factors for hollow core slabs with in-situ reinforced concrete joints, International Journal of Concrete Structures and Materials. 1(2009) 63-69

[8] T. van Overbeek, A. Breunese, J. Gijsbers, K. Both, J. Maljaars, L. Noordijk, New regulations for hollow core slabs after premature partial collapse. $6^{\text {th }}$ International Conference on Structures in Fire. (2010) 141-148.

[9] W. Jansze, A. van Acker, B. Della Bella, R. Klein-Holte, G. Lindström, J.P. Py, M. Scalliet, A. Nitsch, H. Benhöfer, Structural Behaviour of prestressed concrete hollow core floors exposed to fire, BIBM (2014)

[10] CEN. EN 1992-1-2, Eurocode 2: Design of concrete structures. Part 1-2: General rules Structural fire design. Brussels, Belgium: Comité Européen de Normalisation; 2004.

[11] J. V. Aguado, A. Espinos, A. Hospitaler, J. Ortega, M. L. Romero, Influence of reinforcement arrangement in flexural fire behaviour of hollow core slabs, Fire Safety Journal. 53(2012) 72-84 
[12] J.C. Dotreppe, J.M. Franssen, Precast hollow core slabs in fire: numerical simulations and experimental tests, Proceedings of the $3^{\text {rd }}$ International Workshop Structures in Fire.5(2004) 219-232.

[13] I. Venanzi, M. Breccolotti, A. D’Alessandro, A.L. Materazzi, Fire performance assessment of HPLWC hollow core slabs through full-scale furnace testing, Fire Safety Journal. 69(2014) 12-22

[14] J. Fellinger, J. Stark, J. Walraven, Shear and anchorage behaviour of fire exposed hollow core slabs, Heron. 50(2005) 279-301

[15] A. M. Shakya, V. K. R. Kodur, Response of precast prestressed concrete hollowcore slabs under fire conditions. Engineering Structures 87 (2015)126-138

[16] J. Chang, A. H. Buchanan, R. P. Dhakal, P. J. Moss, Simple method for modelling hollowcore concrete slabs under fire, $19^{\text {th }}$ Australian Conference on Mechanics of Structures and Materials. (2006) 463-468

[17] J. Pittr, H. Hartl, Improved stress evaluation under thermal load for simple finite elements, International Journal for Numerical Methods in Engineering. 15(1980) 1507-1515.

[18] S. de Miranda, F. Ubertini, On the consistency of finite element models in thermoelastic analysis, Computer Methods in Applied Mechanics and Engineering. 190(2001) 24112427

[19] ABAQUS. Abaqus Users Manual, 2013. Version 6.13-1, Dassault Systémes Simulia Corp., Providence, Rhode Island, USA

[20] A. Espinos, M. L. Romero, A. Hospitaler, Advanced model for predicting the fire response of concrete filled tubular columns. Journal of Constructional Steel Research 66(2010)1030-1045 
[21] Pascual AM, Romero ML and Tizani W, Fire performance of blind-bolted connections to concrete filled tubular columns in tension, Engineering Structures 2015, doi: 10.1016/j.engstruct.2015.03.067

[22] U. Cicekli, G. Z. Voyiadjis, R. K. Abu Al-Rub, A plasticity and anisotropic damage model for plain concrete. International Journal of Plasticity 23 (2007) 1874-1900

[23] J. A. Purkiss, Fire Safety Engineering. Design of Structures (Second Edition). Oxford, UK: Butterworth-Heinemann-Elsevier Ltd

[24] FIB. Model Code 2010 (Volume 1). Lausanne, Switzerland

[25] J. Fellinger. Shear and anchorage behaviour of fire exposed hollow core slabs. Phd dissertation TU Delft, Delft University Press

[26] V.S. Gopalaratnam, S.P. Shah, Softening response of plain concrete in direct tension. ACI Journal. 82(3)(1985) 310-323

[27] C. V. Nielsen, N. Bicanic, Residual fracture energy of high-performance and normal concrete subject to high temperatures. Materials and Structures 36(2003)515-521

[28] J. Hegger, T. Roggendorf, F. Teworte, M. V. Leskela, FE analyses of shear-loaded hollow-core slabs on different supports. Magazine of Concrete Research 64(2010)531625

[29] Bazant Zdenek P., Pere C. Prat, Effect of Temperature and Humidity on Fractuer Energy of Concrete. ACI Materials Journal 85(1988)262-271

[30] CEN. EN 1991-1-2, Eurocode 1: Actions on structures. Part 1-2: General actions Actions on structures exposed to fire. Brussels, Belgium: Comité Européen de Normalisation; 2002

[31] N. E. Andersen, D. H. Lauridsen, DIFT Technical Report X 52650. Hollow Core Slabs. Danish Institute of Fire Technology (1999) 
Aguado JV, Albero V, Espinos A, Hospitaler A, Romero ML. A 3D finite element model for predicting the fire behavior of hollowcore slabs. Eng. Struct. 2016; 108C:12-27. doi: 10.1016/j.engstruct.2015.11.008

[32] W. Borgogno, M. Fontana, Structural behavior of slim floor slabs with prestressed hollow core elements at room temperature and in fire. Composite construction in steel and concrete IV (2000)768-779

[33] CEN. EN 1168:2005+A3:2011, Precast concrete products - Hollow core slabs. Brussels, Belgium: Comité Européen de Normalisation; 2011 
Aguado JV, Albero V, Espinos A, Hospitaler A, Romero ML. A 3D finite element model for predicting the fire behavior of hollowcore slabs. Eng. Struct. 2016; 108C:12-27. doi: 10.1016/j.engstruct.2015.11.008

a)

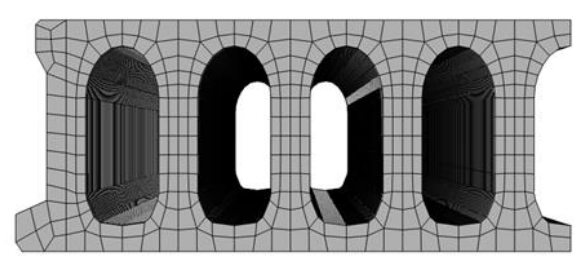

b)

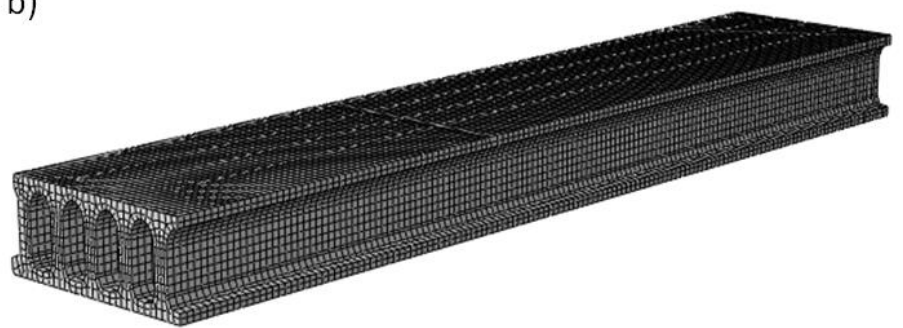

Figure 1. a) Cross-sectional mesh. b) General view of the mesh 
a)

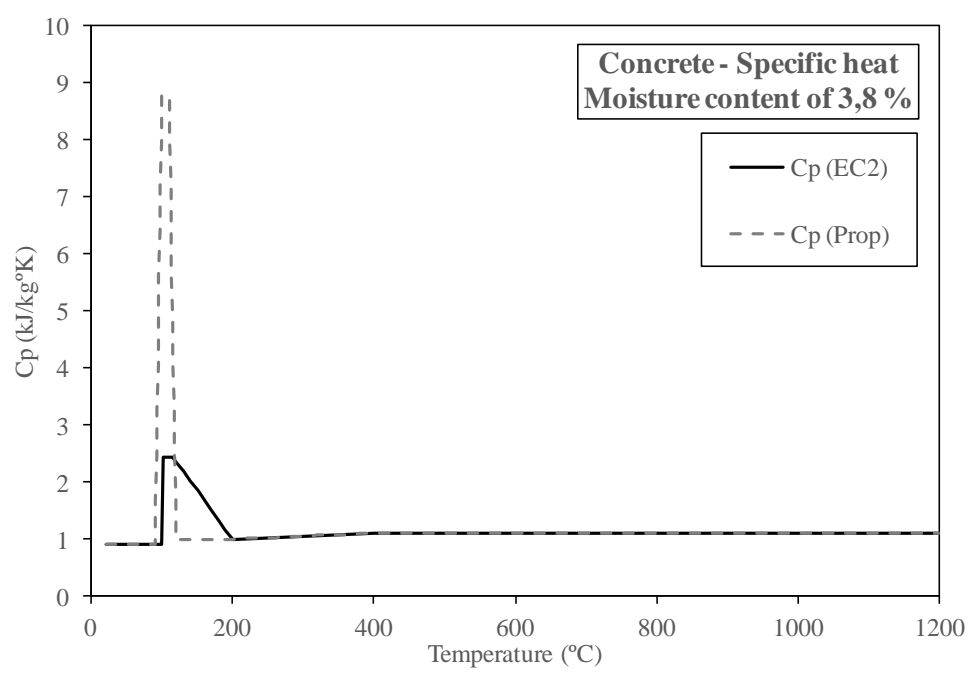

b)

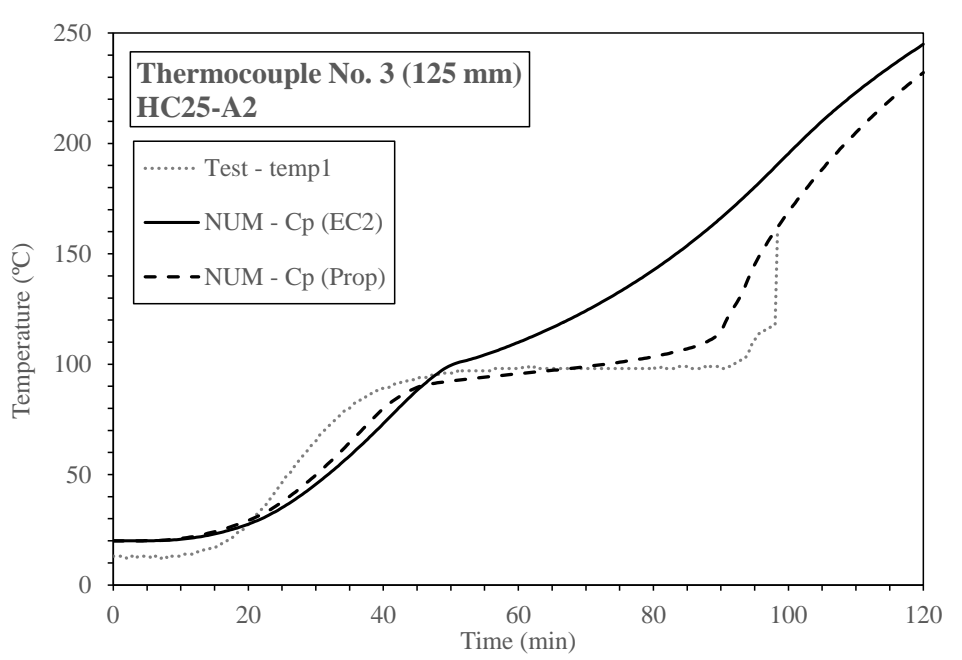

c)

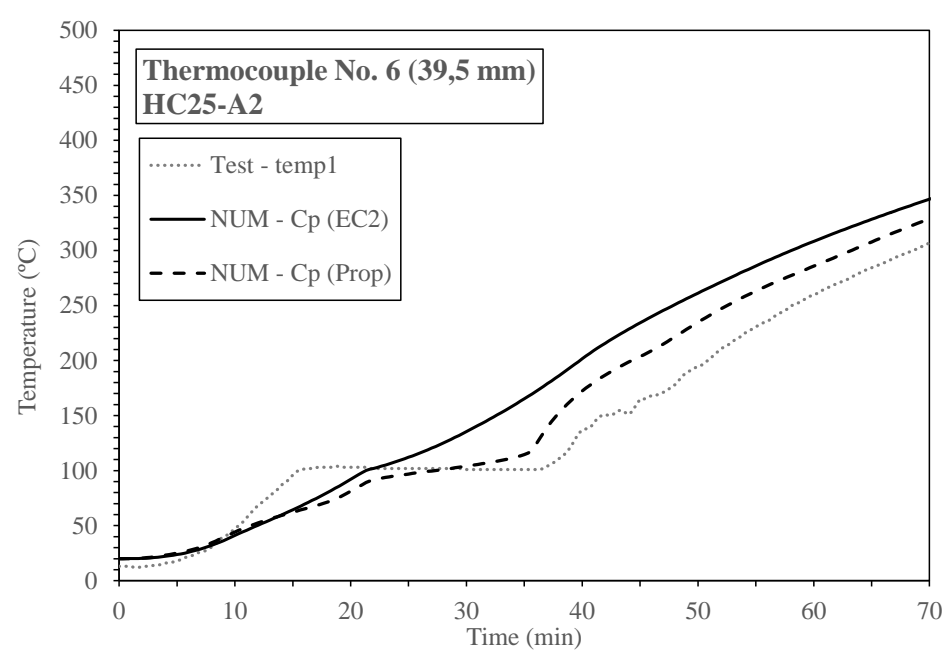

Figure 2. Specific heat of concrete. a) Comparison between EC2 and proposed model. b) Improvement of the numerical response (125mm from the bottom surface). c) Improvement of the numerical response $(39.5 \mathrm{~mm}$ from the bottom surface) 
Aguado JV, Albero V, Espinos A, Hospitaler A, Romero ML. A 3D finite element model for predicting the fire behavior of hollowcore slabs. Eng. Struct. 2016; 108C:12-27. doi: 10.1016/j.engstruct.2015.11.008

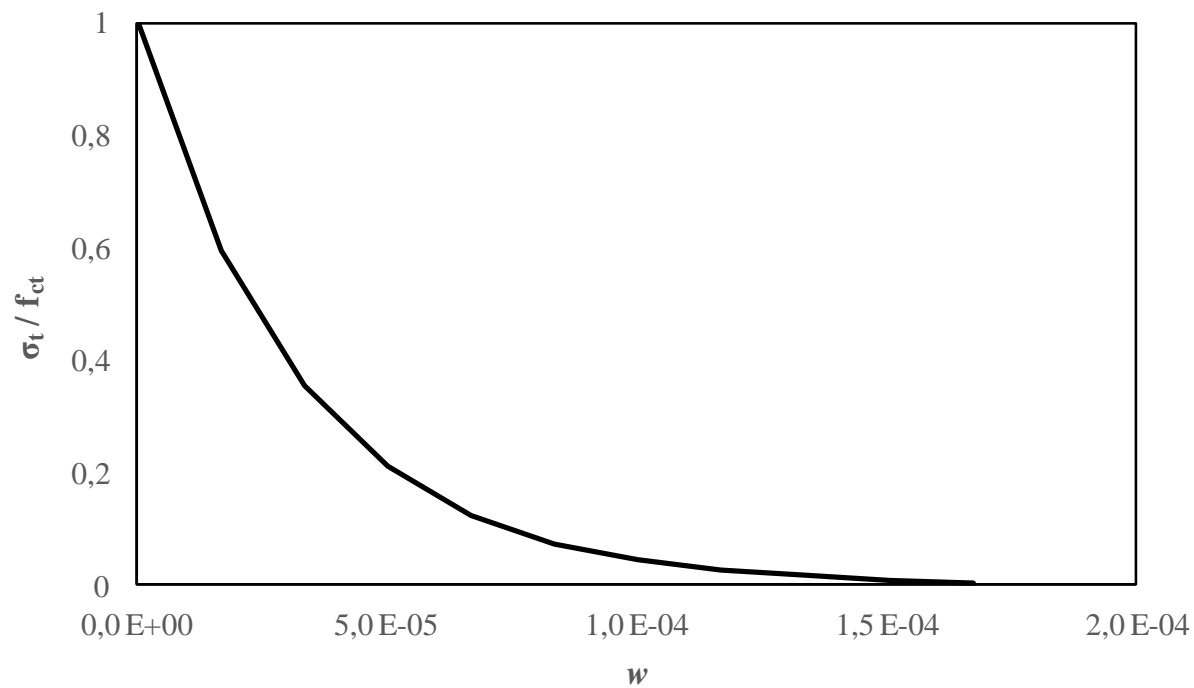

Figure 3. Tensile stress versus crack opening relation, [27], [28]. 
Aguado JV, Albero V, Espinos A, Hospitaler A, Romero ML. A 3D finite element model for predicting the fire behavior of hollowcore slabs. Eng. Struct. 2016; 108C:12-27. doi: 10.1016/j.engstruct.2015.11.008

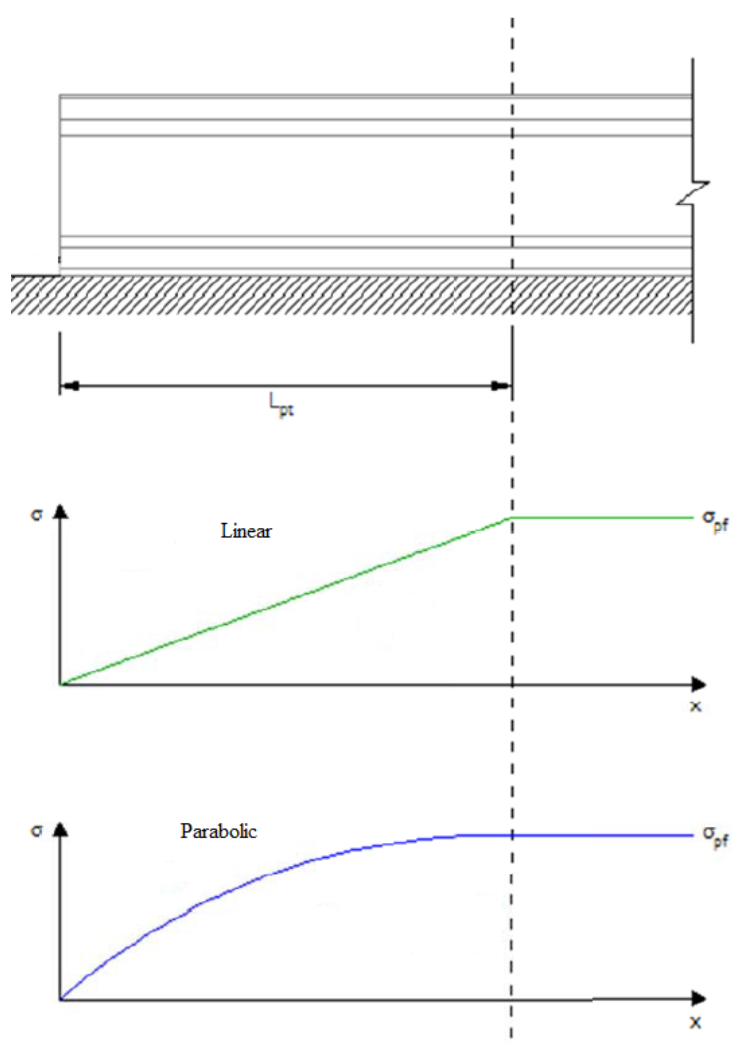

Figure 4. Transmission length and shape function 


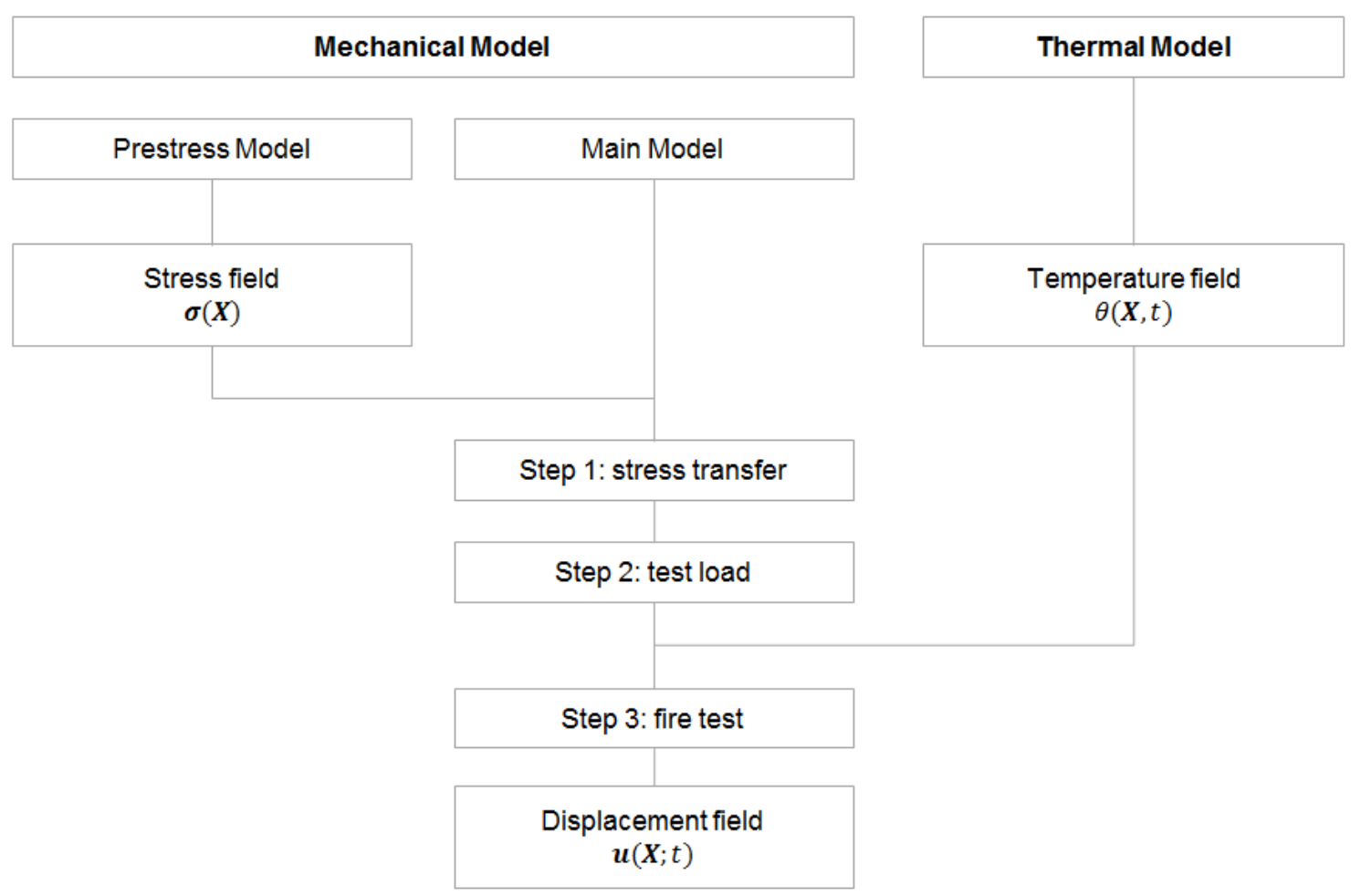

Figure 5. General scheme of the numerical model 
Aguado JV, Albero V, Espinos A, Hospitaler A, Romero ML. A 3D finite element model for predicting the fire behavior of hollowcore slabs. Eng. Struct. 2016; 108C:12-27. doi: 10.1016/j.engstruct.2015.11.008

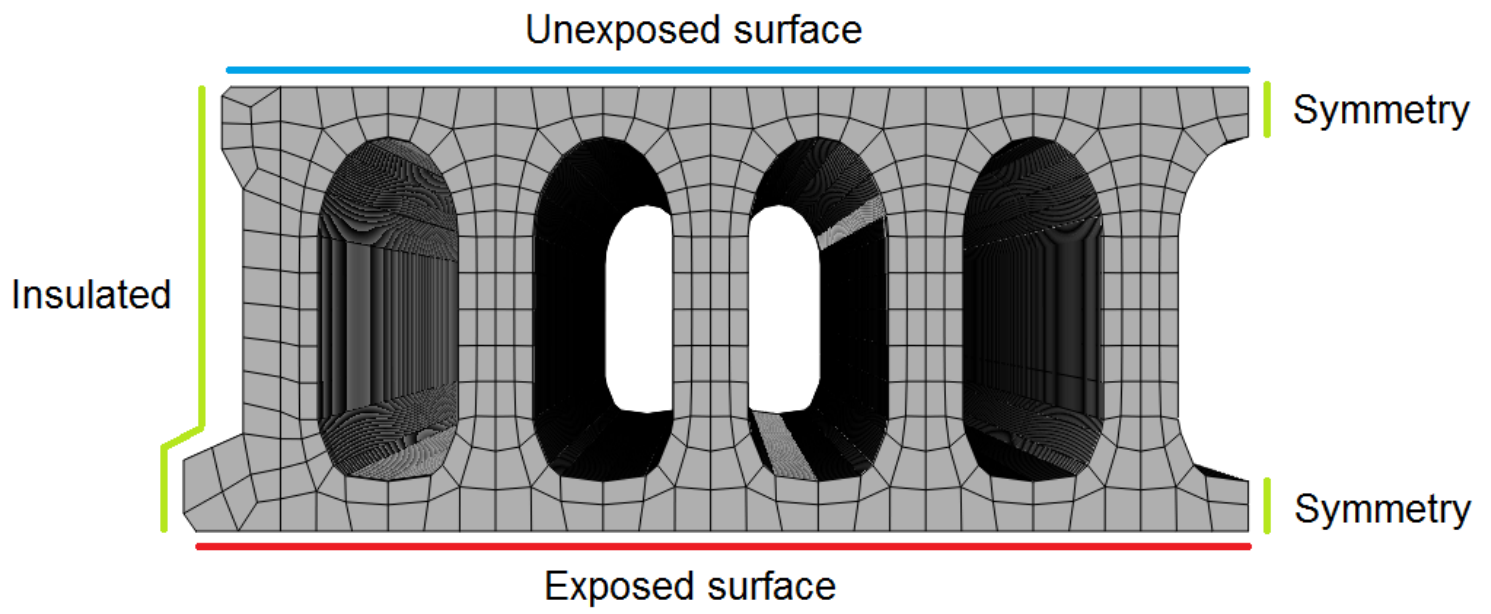

Figure 6. Boundary surfaces of the thermal model 


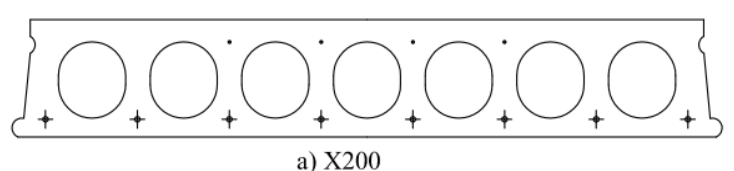

a) X200

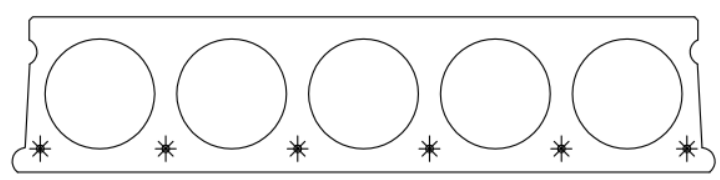

c) VX265

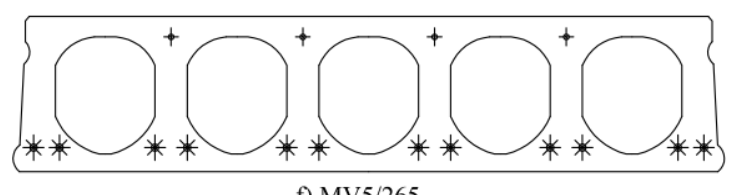

f) MV5/265

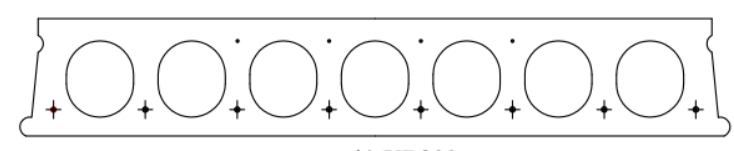

b) XB200

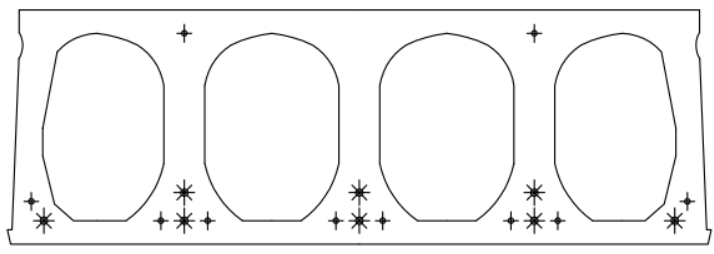

d) $\mathrm{K} 400$

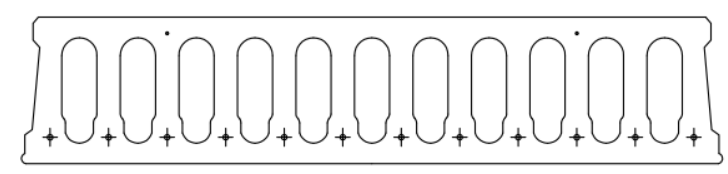

g) VMM VSD25

Figure 7. Cross-section and reinforcement arrangement of the HC slabs used for validation at room

temperature [5], [25] 
Aguado JV, Albero V, Espinos A, Hospitaler A, Romero ML. A 3D finite element model for predicting the fire behavior of hollowcore slabs. Eng. Struct. 2016; 108C:12-27. doi: 10.1016/j.engstruct.2015.11.008

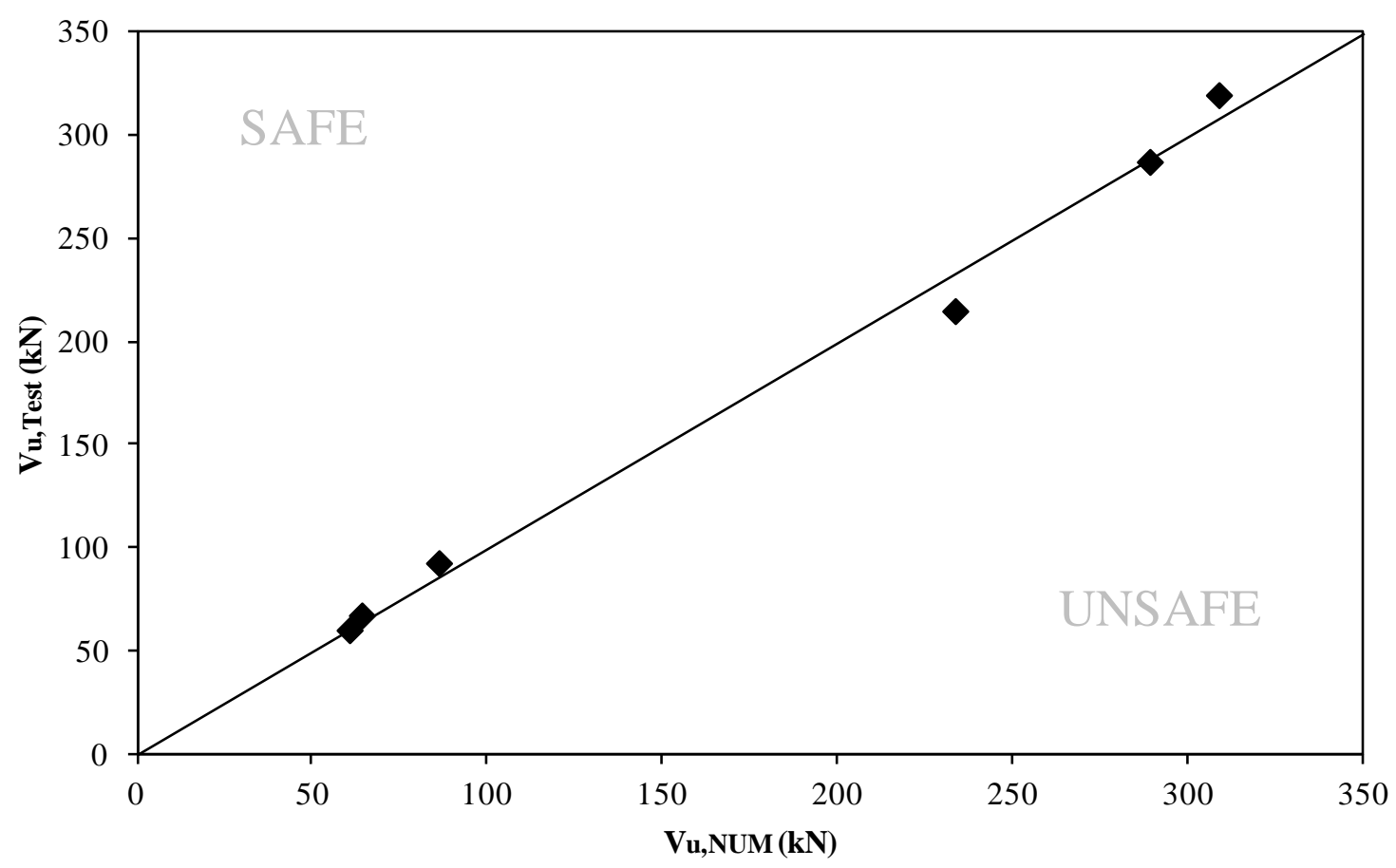

Figure 8. Comparison of numerical and test results at room temperature 


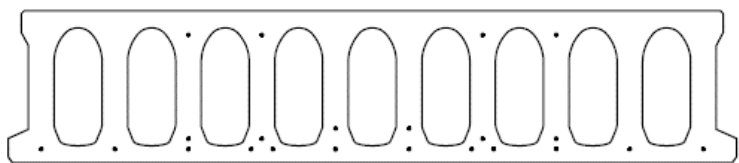

a) $\mathrm{HC} 25-\mathrm{A} 1$

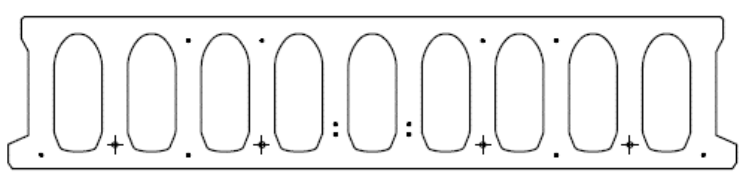

c) $\mathrm{HC} 25-\mathrm{A} 3$

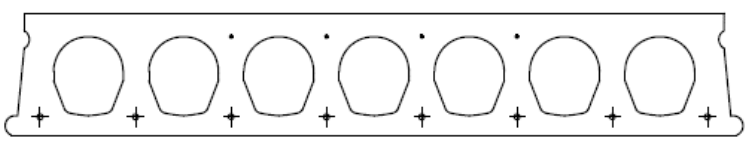

e) A200

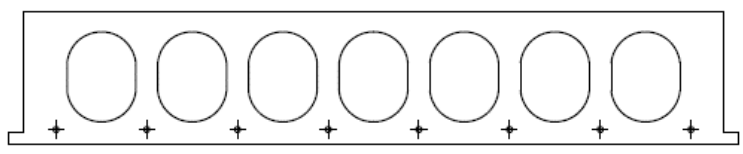

g) SP22

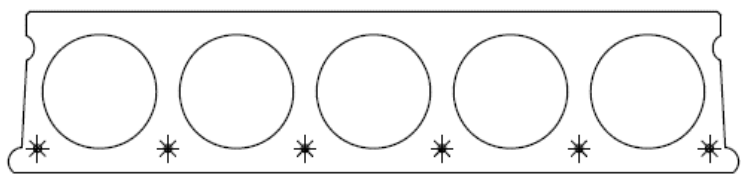

i) VX265

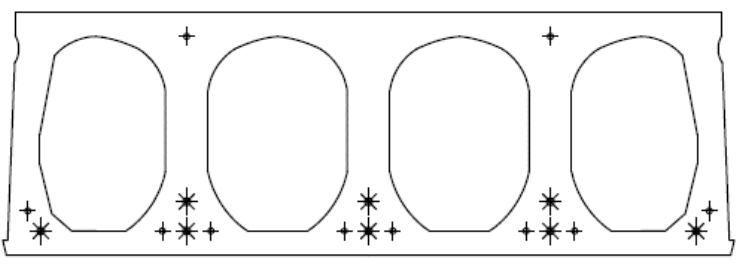

k) K400

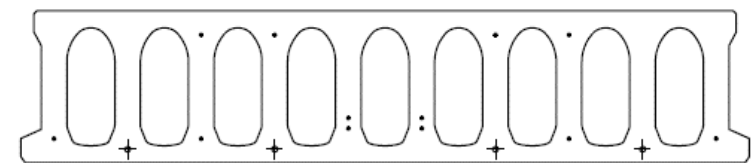

b) $\mathrm{HC} 25-\mathrm{A} 2$

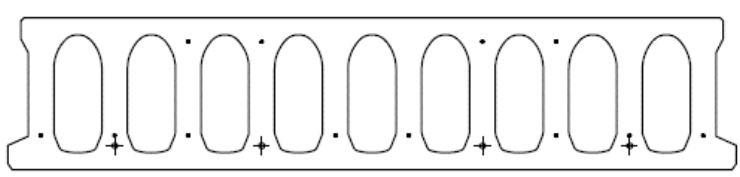

d) $\mathrm{HC} 25-\mathrm{A} 4$

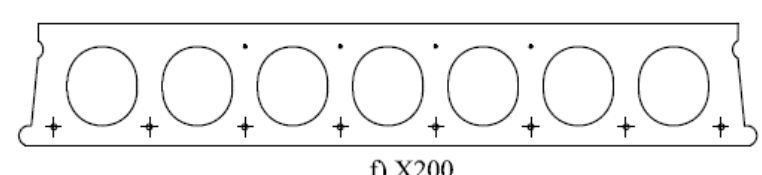

f) $\mathrm{X} 200$

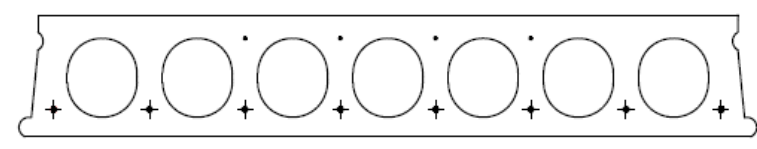

h) XB200

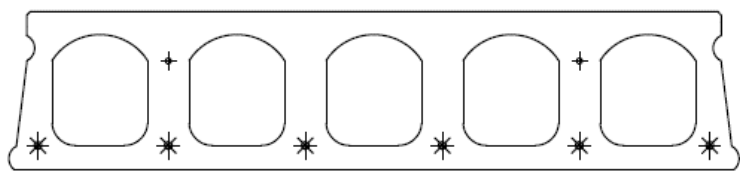

j) HVP260

- Wire $\$ 3 / 8^{\prime \prime}$ strand * * $1 / 2^{\prime \prime}$ strand

Figure 9. Cross-section and reinforcement arrangement of the $\mathrm{HC}$ slabs used for validation at high temperature [11], [25], [31] 


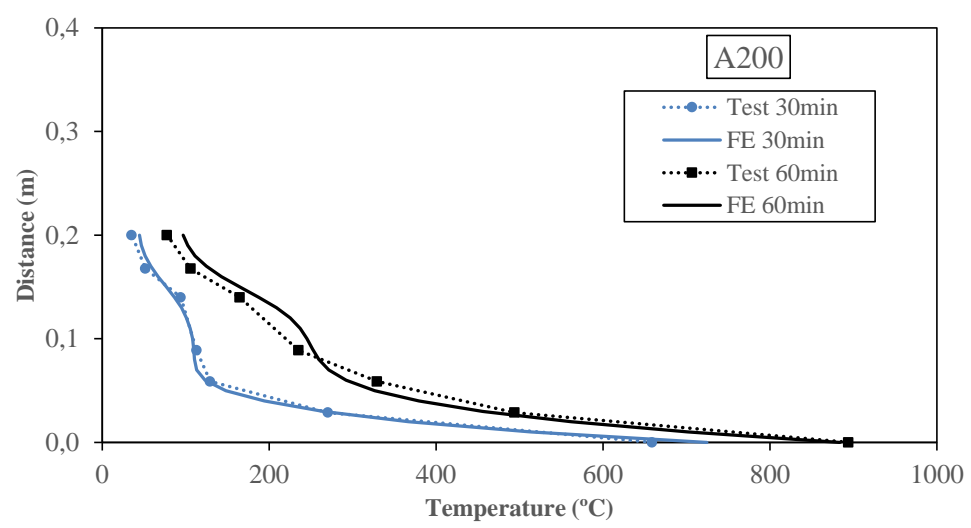

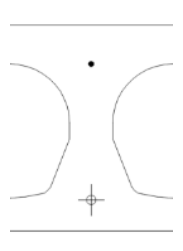

$\mathbf{A 2 0 0}$
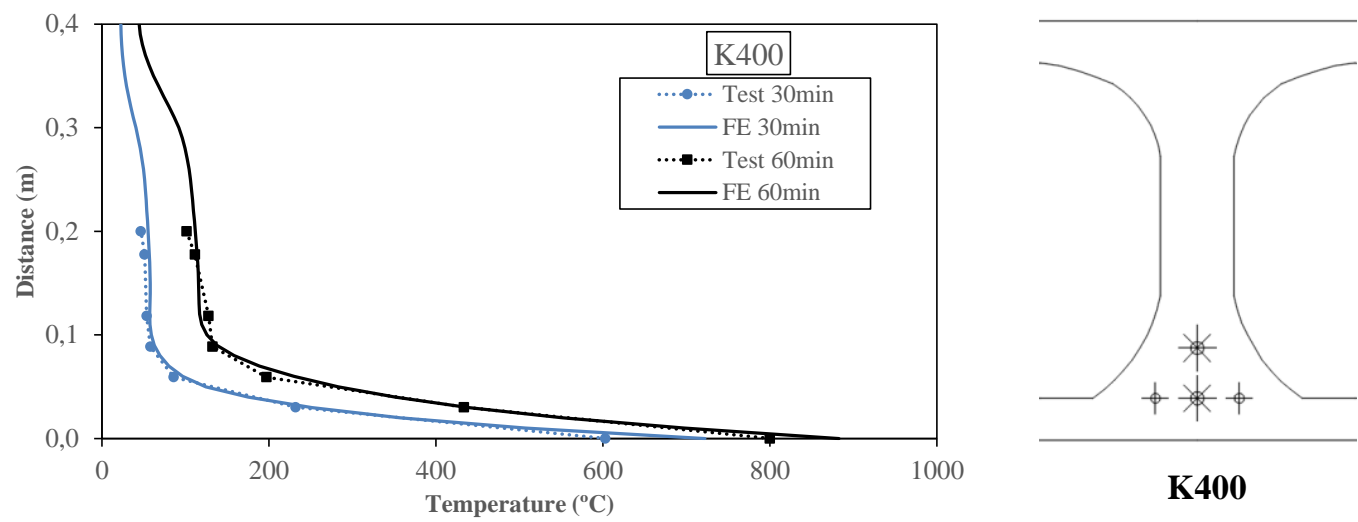

K400

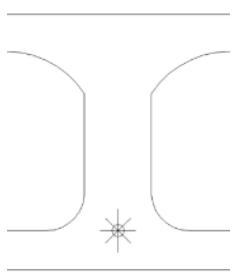

HVP 260

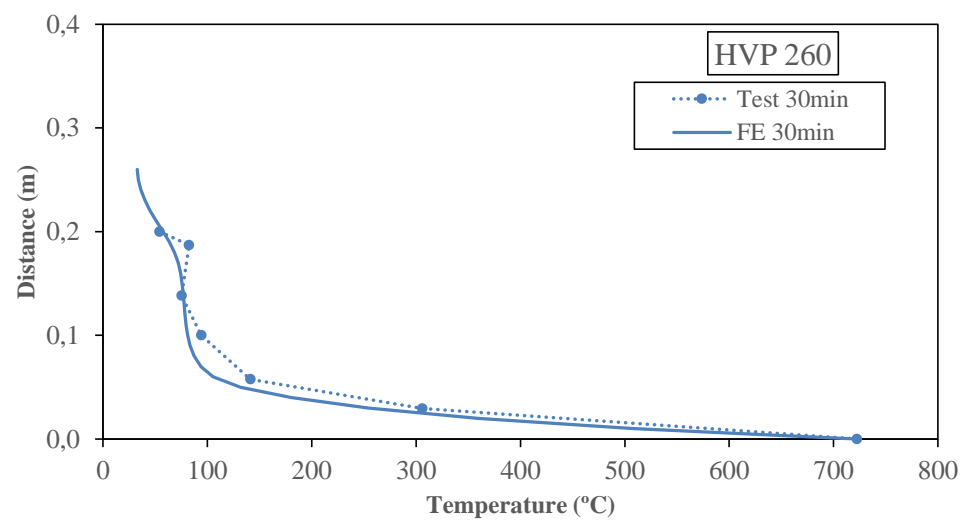

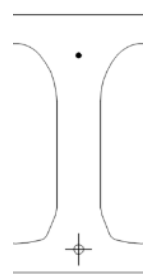

HC25-A2

Figure 10. Comparison of temperatures from numerical model (FE) and experimental test 
Aguado JV, Albero V, Espinos A, Hospitaler A, Romero ML. A 3D finite element model for predicting the fire behavior of hollowcore slabs. Eng. Struct. 2016; 108C:12-27. doi: 10.1016/j.engstruct.2015.11.008

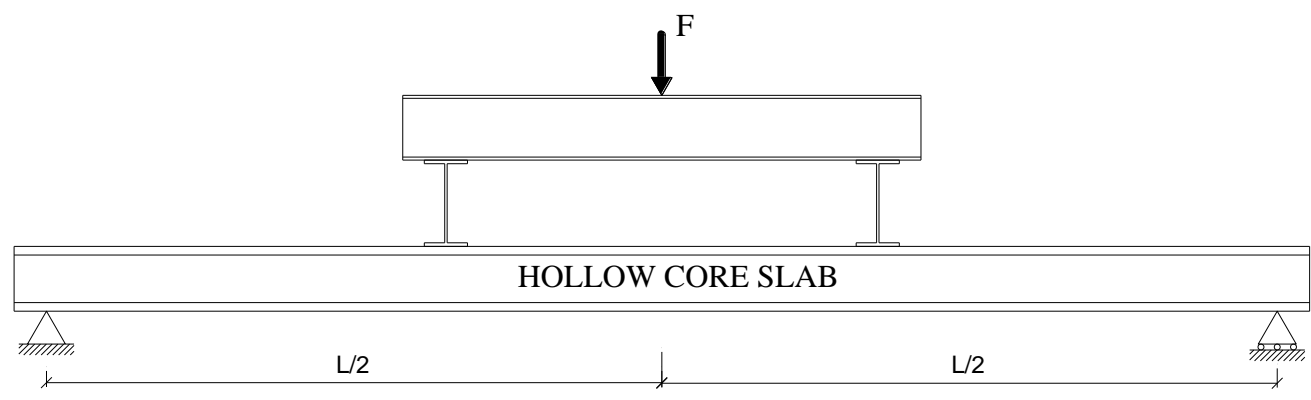

a) Flexural test scenario

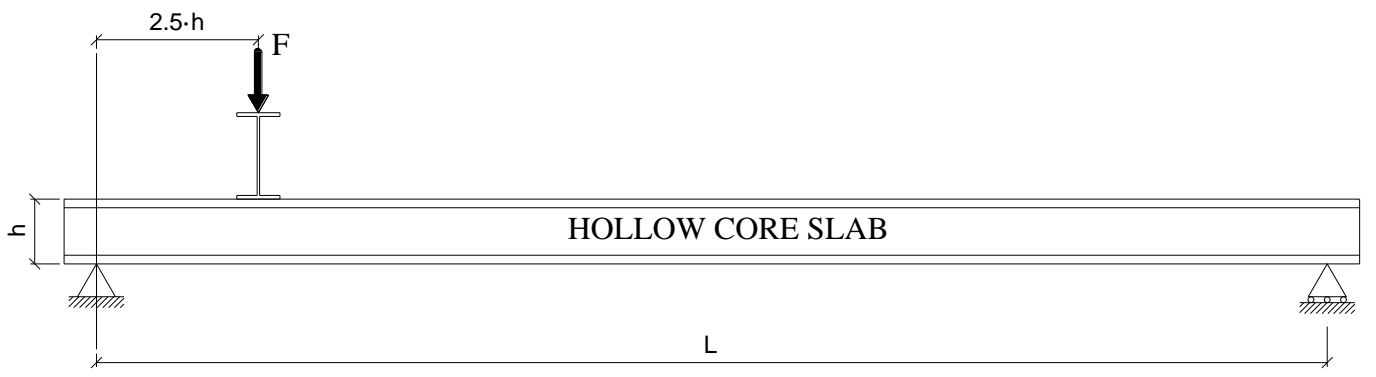

b) Shear test scenario

Figure 11. Test scenarios 
Aguado JV, Albero V, Espinos A, Hospitaler A, Romero ML. A 3D finite element model for predicting the fire behavior of hollowcore slabs. Eng. Struct. 2016; 108C:12-27. doi: 10.1016/j.engstruct.2015.11.008

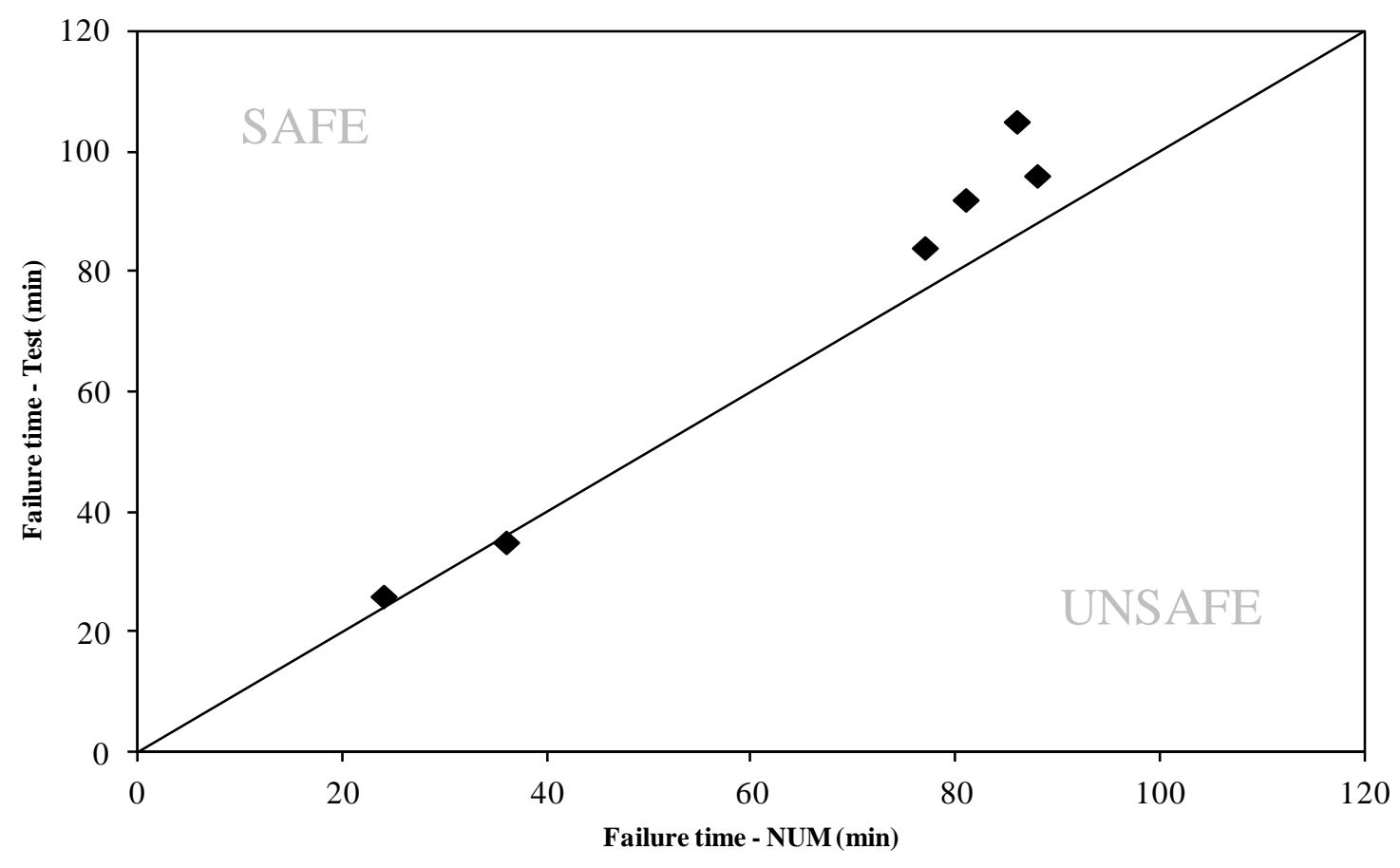

Figure 12. Comparison of numerical and test results at high temperature 
a)

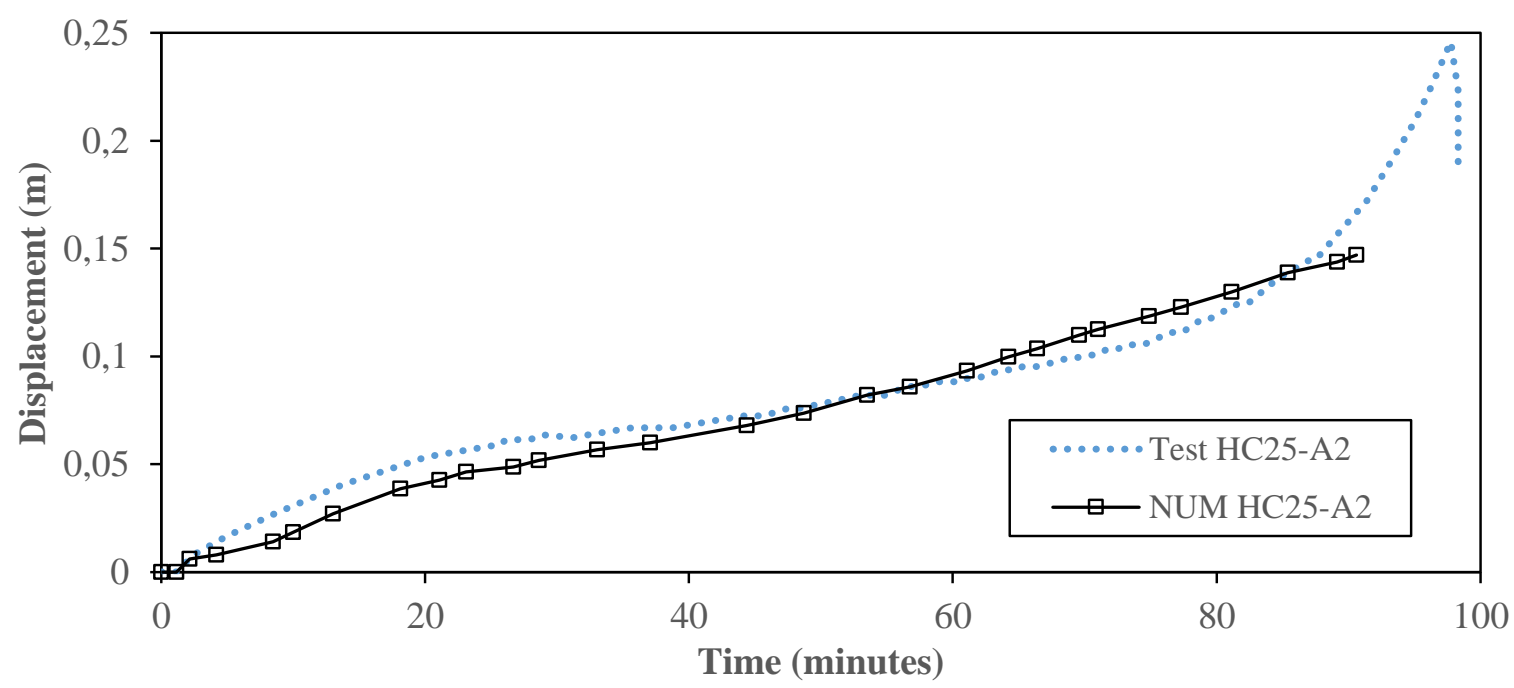

b)

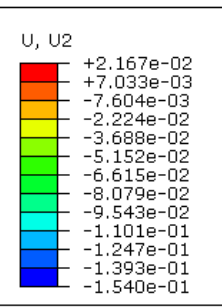

Figure 13. HC25-A2. a) Mid-span deflection. d) Deformed shape 


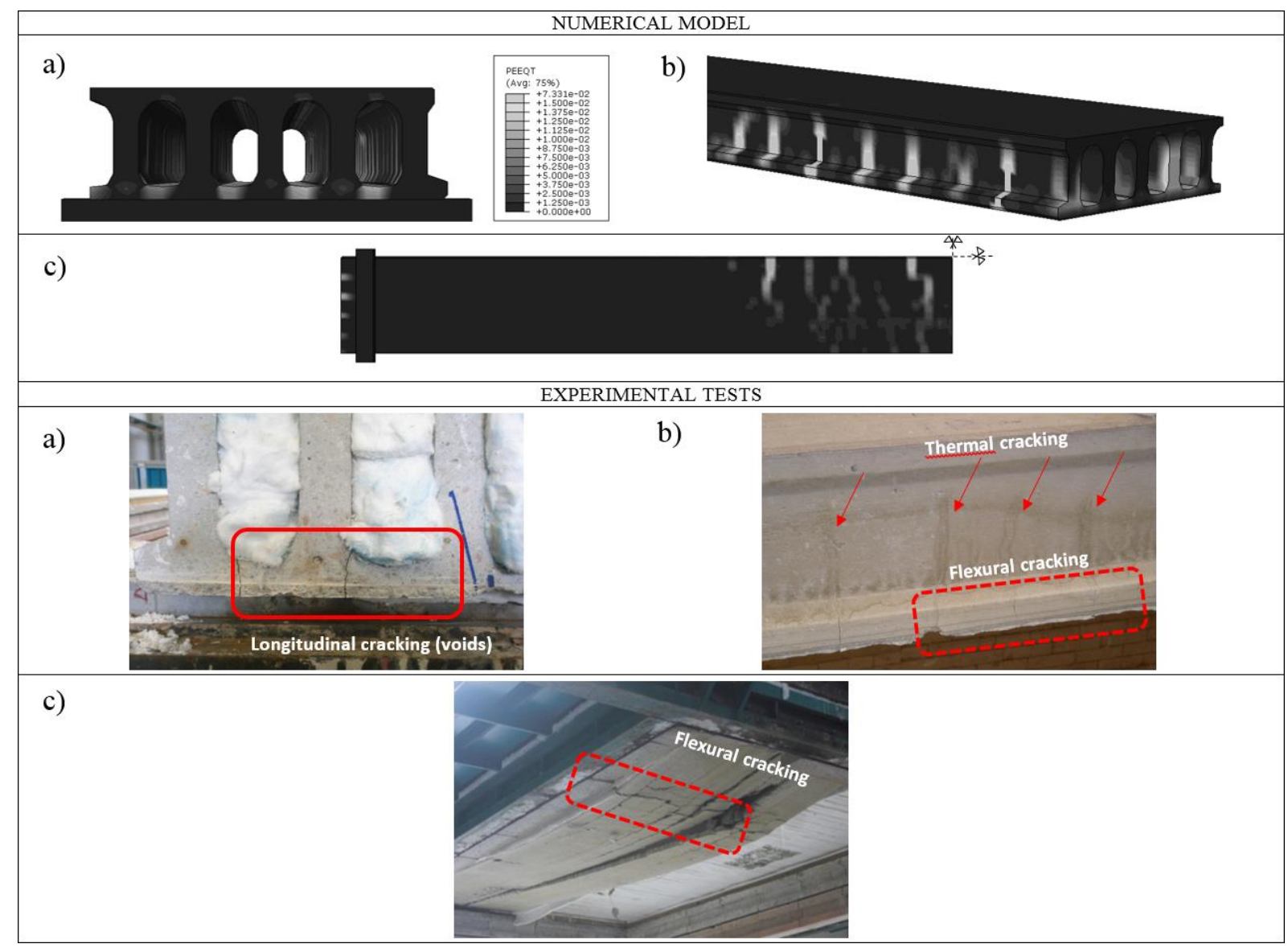

Figure 14. Cracking patterns HC25-A2. a) Longitudinal cracking near the support. b) Thermal and flexural cracking near the central area. c) Bottom view of flexural cracking 


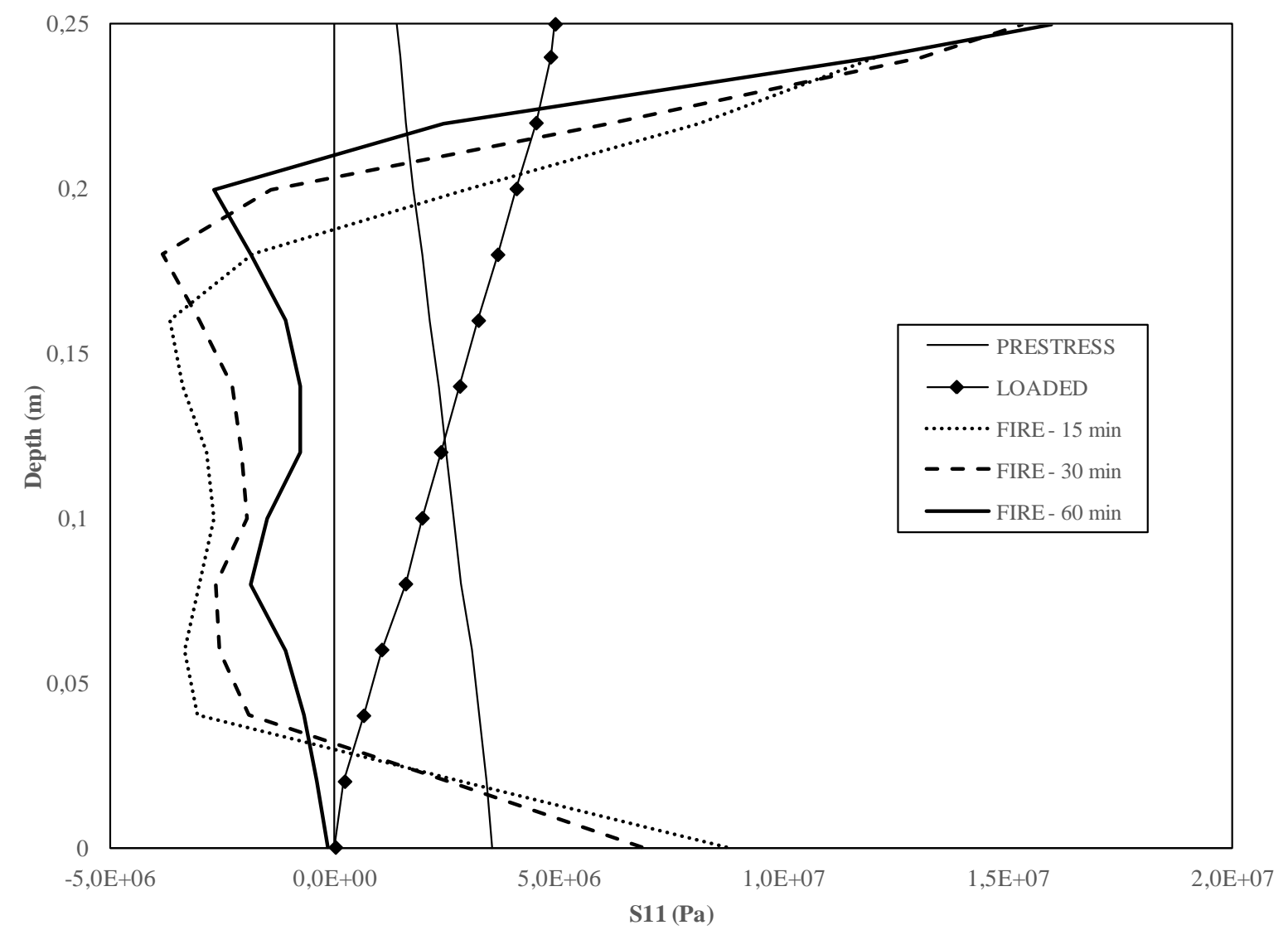

Figure 15.HC25-A2 Stress evolution from numerical model along web height 

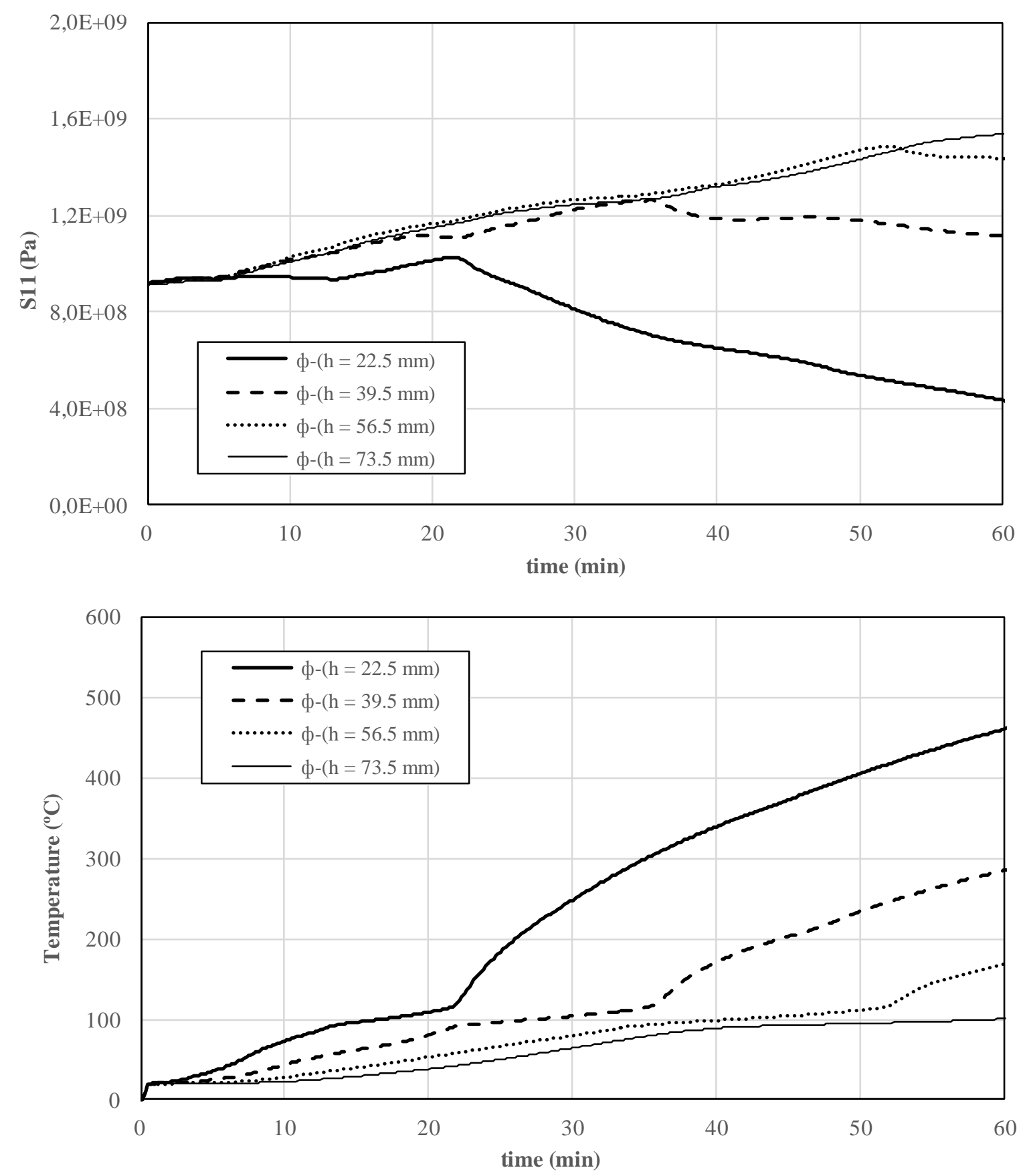

Figure 16. HC25-A2 Stress and temperature evolution in tendons from numerical model 


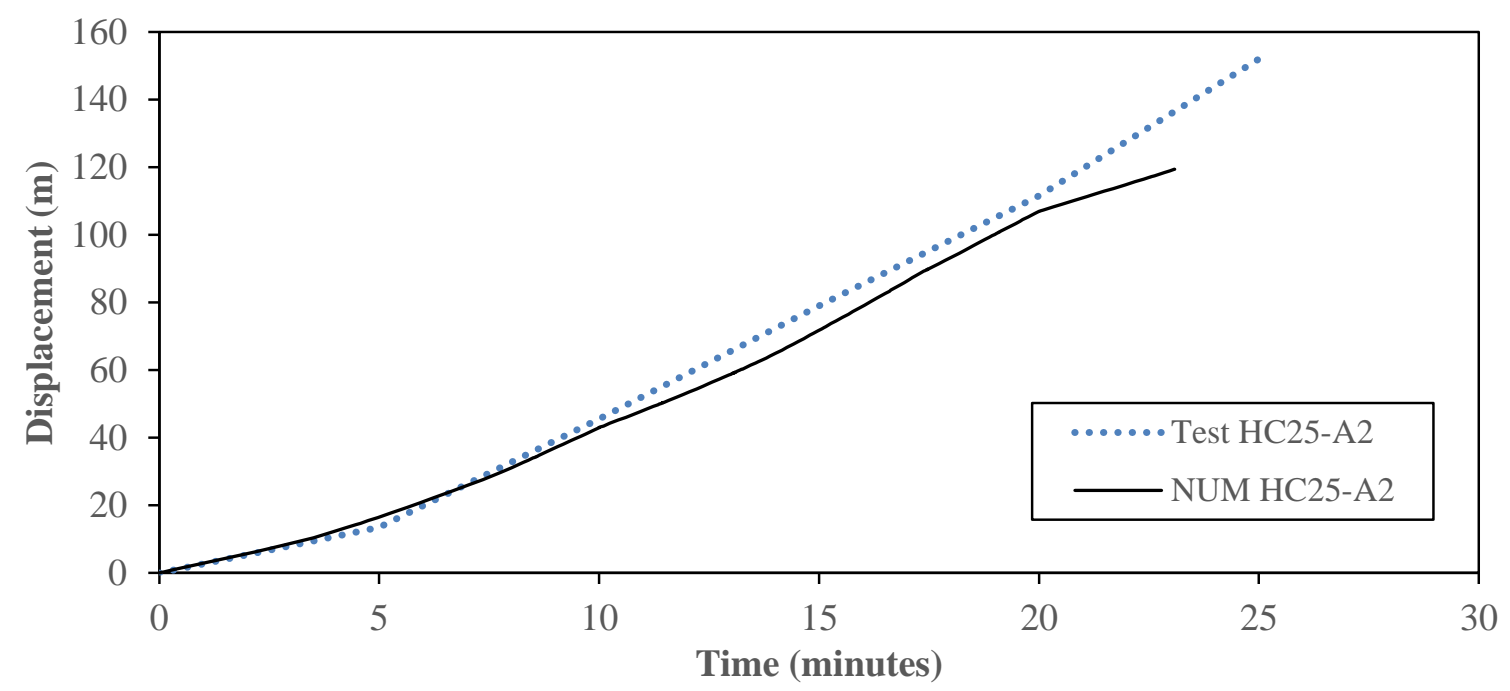

Figure 17. SP-22 mid-span deflection 


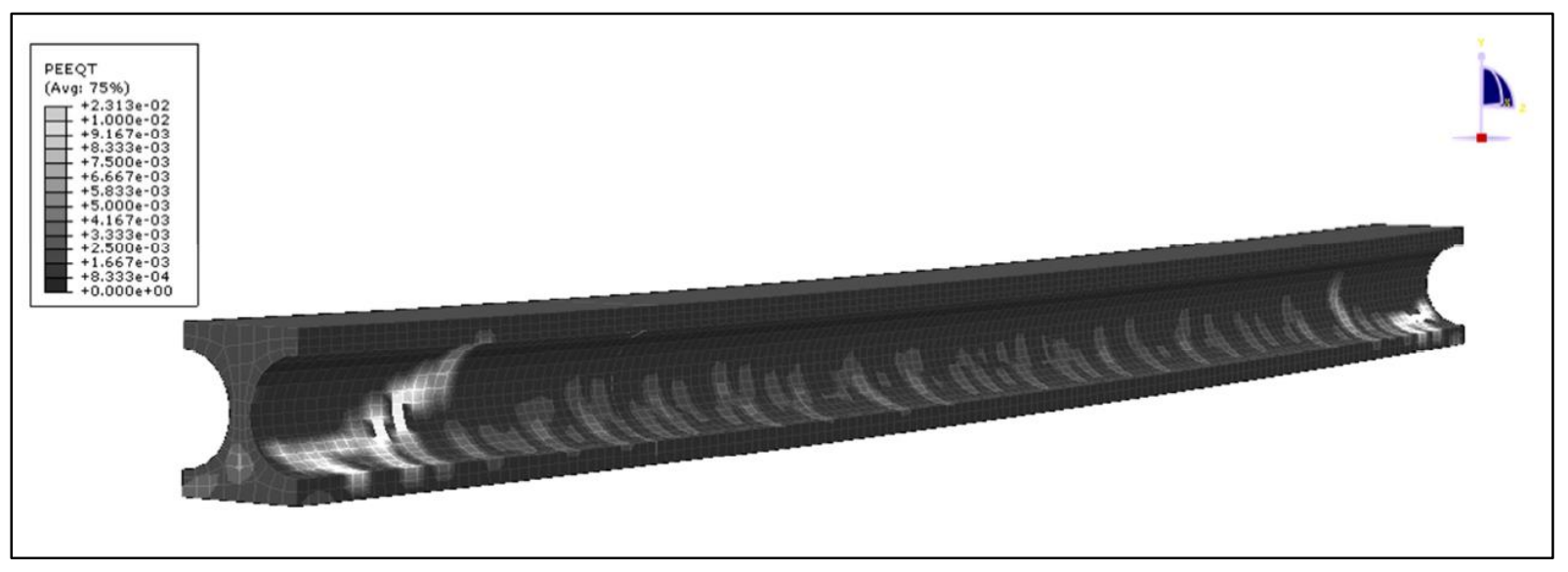

Figure 18. VX265 Shear failure from numerical model 


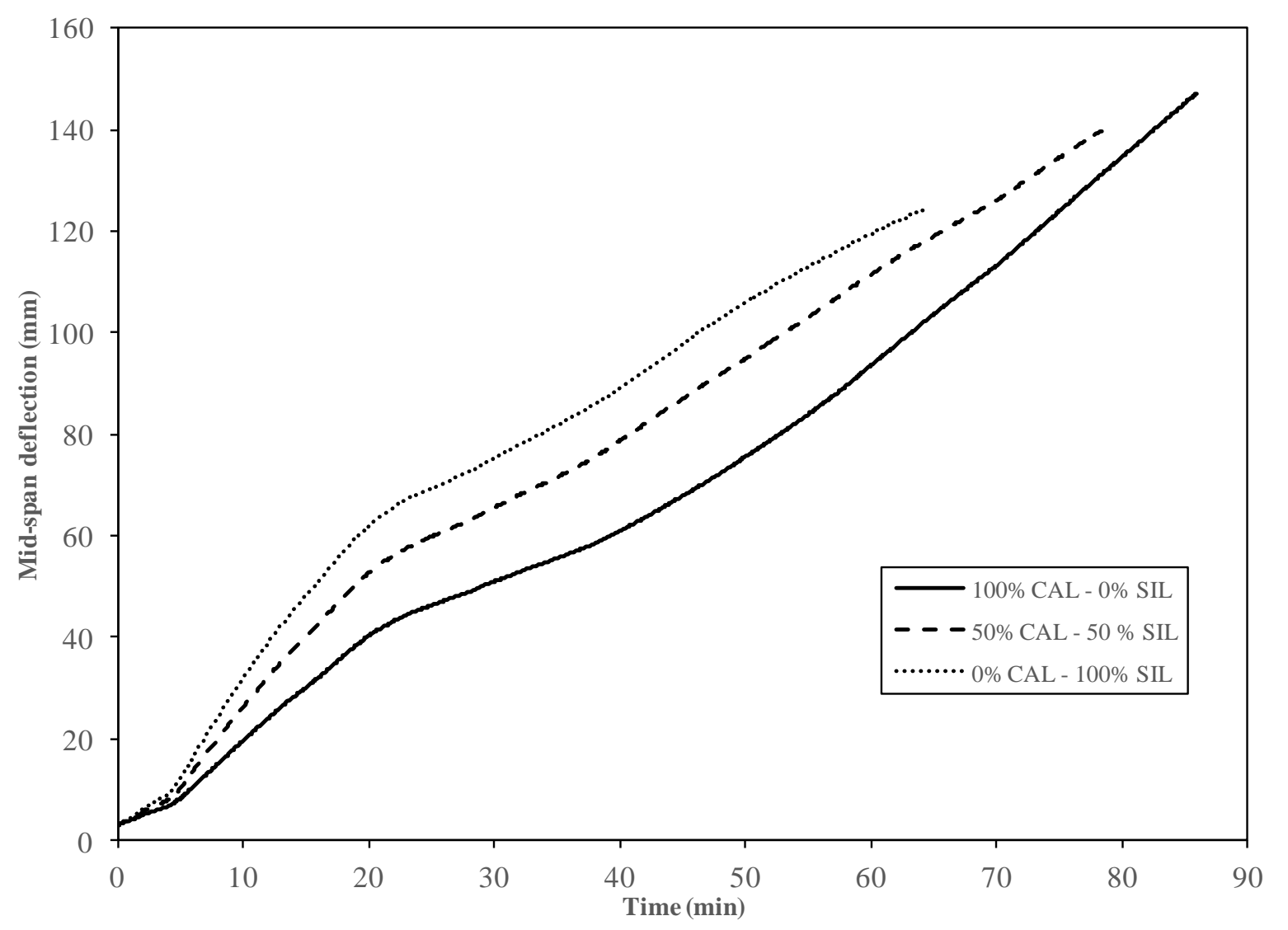

Figure 19. Mechanical response with different aggregate type mixture 


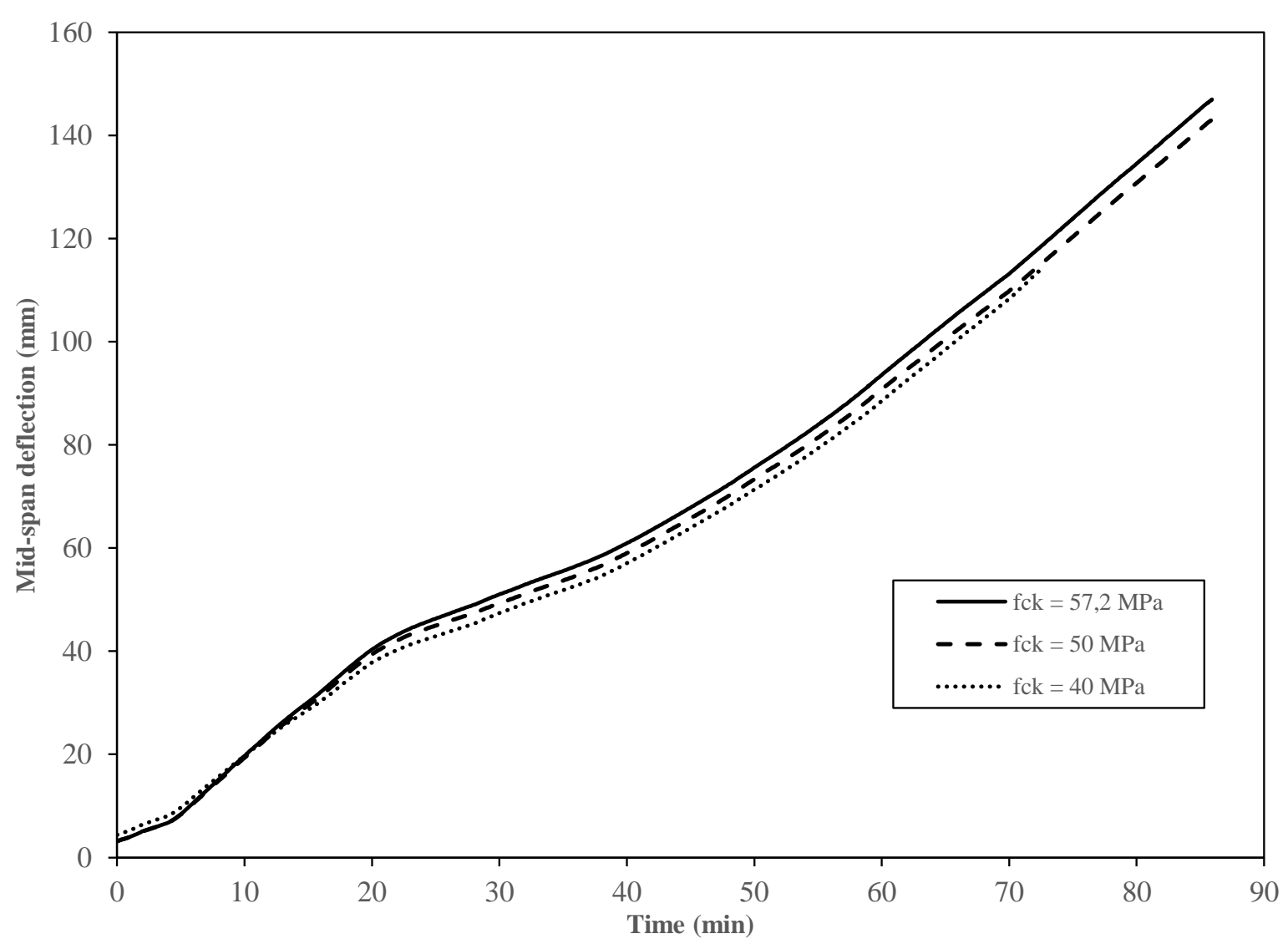

Figure 20. Mechanical response with different concrete strength 


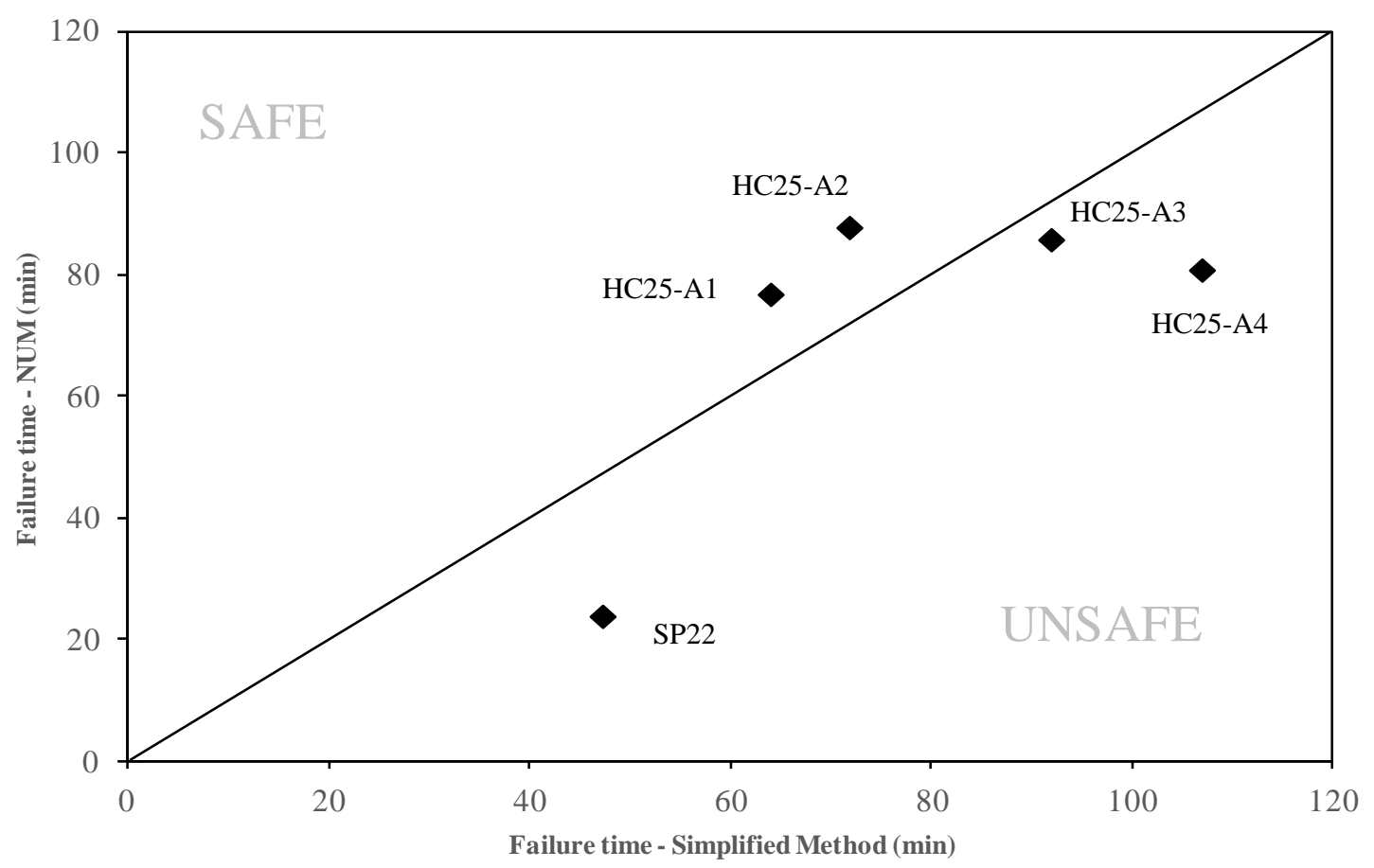

Figure 21. Comparison between numerical and simplified method results at high temperatures 
Table 1. Geometry of the specimens used in the numerical simulations at room temperature

\begin{tabular}{|c|c|c|c|c|c|c|c|c|}
\hline \multicolumn{9}{|c|}{ Geometric parameters } \\
\hline Source & Id. & $\mathrm{H}$ & B & $\mathrm{Nw} / \mathrm{Ww}$ & $\mathrm{Nh} / \mathrm{Wh}$ & $\mathrm{Hh}$ & $\mathrm{TFt}$ & $\mathrm{BFt}$ \\
\hline \multirow{3}{*}{$\begin{array}{c}\text { Fellinger } \\
\text { [25] }\end{array}$} & X200 / XB200 & 200 & 1200 & $8 / 42$ & $7 / 115$ & 130 & 38 & 32 \\
\hline & VX265 & 265 & 1200 & $6 / 38$ & $5 / 185$ & 185 & 40 & 40 \\
\hline & $\mathrm{K} 400$ & 400 & 1200 & $5 / 70$ & $4 / 212$ & 320 & 40 & 40 \\
\hline \multirow{2}{*}{$\begin{array}{c}\text { Hegger } \\
{[5]}\end{array}$} & MV5/265 & 265 & 1200 & $6 / 55$ & $5 / 167$ & 200 & 35 & 30 \\
\hline & VMM VSD25 & 250 & 1200 & $12 / 40$ & $11 / 60$ & 180 & 35 & 35 \\
\hline \multicolumn{9}{|c|}{ Reinforcement parameters } \\
\hline \multirow{2}{*}{ Source } & \multirow{2}{*}{ Id. } & \multicolumn{3}{|c|}{ Axis distance (mm) / Reinforcement } & \multirow{2}{*}{\multicolumn{4}{|c|}{ Ap }} \\
\hline & & Row 1 & Row 2 & Row 3 & & & & \\
\hline \multirow{4}{*}{$\begin{array}{c}\text { Fellinger } \\
\text { [25] }\end{array}$} & X200 & $30 / 8 \phi 9.3$ & $165 / 4 \phi 5$ & - & \multicolumn{4}{|c|}{$494.5 \mathrm{~mm}^{2}$} \\
\hline & XB200 & $45 / 8 \phi 9.3$ & $165 / 4 \phi 5$ & - & \multicolumn{4}{|c|}{$494.5 \mathrm{~mm}^{2}$} \\
\hline & VX265 & 40/6ф13 & - & - & \multicolumn{4}{|c|}{$600 \mathrm{~mm}^{2}$} \\
\hline & K400 & $40 / 8 \phi 13$ & 88/8ф9.3 & $360 / 2 \phi 6.9$ & \multicolumn{4}{|c|}{$1365.6 \mathrm{~mm}^{2}$} \\
\hline \multirow{2}{*}{$\begin{array}{c}\text { Hegger } \\
{[5]}\end{array}$} & MV5/265 & $41 / 12 \phi 13$ & $230 / 2 \phi 9.3$ & - & \multicolumn{4}{|c|}{$1304 \mathrm{~mm}^{2}$} \\
\hline & VMM VSD25 & $42 / 12 \phi 13$ & $222.5 / 2 \phi 5$ & - & \multicolumn{4}{|c|}{$1239.3 \mathrm{~mm}^{2}$} \\
\hline
\end{tabular}

H: Slab height

B: Slab width

Nw: Number of webs

Ww: Web width

Nh: Number of holes
Wh: Hole width

Hh: Hole height

TFt: Top flange thickness

BFt: Bottom flange thickness

Ap: Prestress area 
Table 2. Comparison of numerical and test results at room temperature

\begin{tabular}{|c|c|c|c|c|c|c|}
\hline \multirow{2}{*}{ Source } & \multirow{2}{*}{ Id. } & \multicolumn{2}{|c|}{ Failure Mode } & \multirow{2}{*}{$\mathrm{V}_{\mathrm{u}, \text { Test }}(\mathrm{kN})$} & \multirow{2}{*}{$\mathrm{V}_{\mathrm{u}, \mathrm{NUM}}(\mathrm{kN})$} & \multirow{2}{*}{$\begin{array}{c}\xi_{\mathrm{Vu}} \\
(\text { Test/NUM) }\end{array}$} \\
\hline & & Test & Num & & & \\
\hline \multirow{4}{*}{$\begin{array}{c}\text { Fellinger } \\
{[25]}\end{array}$} & $\mathrm{X} 200$ & Flex & 66.63 & 66.63 & 64.36 & 1.04 \\
\hline & XB 200 & Flex. & 59.50 & 59.50 & 60.86 & 0.98 \\
\hline & VX265 & Shear & 92.03 & 92.03 & 86.40 & 1.07 \\
\hline & K400 & Shear & 214.37 & 214.37 & 233.86 & 0.92 \\
\hline \multirow{2}{*}{$\begin{array}{c}\text { Hegger } \\
{[5]}\end{array}$} & MV5/265 & Shear & 286.80 & 286.80 & 289.45 & 0.99 \\
\hline & VMM VSD25 & Shear & 319.20 & 319.20 & 309.18 & 1.03 \\
\hline & & & & \multicolumn{2}{|c|}{ Average $\xi_{\mathrm{vu}}$} & 1.00 \\
\hline & & & & \multicolumn{2}{|c|}{ Standard deviation } & 0.05 \\
\hline
\end{tabular}


Table 3a. Geometry of the specimens used in the numerical simulations at high temperature

Geometric parameters

\begin{tabular}{|c|c|c|c|c|c|c|c|c|}
\hline Source & Id. & $\mathrm{H}$ & B & $\mathrm{Nw} / \mathrm{Ww}$ & $\mathrm{Nh} / \mathrm{Wh}$ & $\mathrm{Hh}$ & $\mathrm{TFt}$ & $\mathrm{BFt}$ \\
\hline $\begin{array}{c}\text { Aguado et al. } \\
\text { [11] }\end{array}$ & $\begin{array}{c}\mathrm{HC} 25 \\
{[\mathrm{~A} 1-\mathrm{A} 4]}\end{array}$ & 250 & 1200 & $10 / 42$ & $9 / 79$ & 194 & 28 & 28 \\
\hline $\begin{array}{c}\text { Andersen and } \\
\text { Lauridsen } \\
{[31]}\end{array}$ & SP22 & 220 & 1200 & $8 / 36$ & $7 / 114$ & 149 & 35.5 & 35.5 \\
\hline \multirow{5}{*}{$\begin{array}{c}\text { Fellinger }^{* 1} \\
{[25]}\end{array}$} & A200 & 200 & 314 & $2 / 40$ & $1 / 117$ & 130 & 38 & 32 \\
\hline & X200/XB200 & 200 & 314 & $2 / 42$ & $1 / 115$ & 130 & 38 & 32 \\
\hline & VX265 & 265 & 446 & $2 / 38$ & $1 / 185$ & 185 & 40 & 40 \\
\hline & HVP260 & 260 & 450 & $2 / 65$ & $1 / 160$ & 180 & 40 & 40 \\
\hline & K400 & 400 & 564 & $2 / 70$ & $1 / 212$ & 320 & 40 & 40 \\
\hline $\begin{array}{l}\text { (*1): Double ribs were } \\
\text { H: Slab height } \\
\text { B: Slab width } \\
\text { Nw: Number of webs } \\
\text { Ww: Web width } \\
\text { Nh: Number of holes }\end{array}$ & \multicolumn{8}{|c|}{$\begin{array}{l}\text { Wh: Hole width } \\
\text { Hh: Hole height } \\
\text { TFt: Top flange thickness } \\
\text { BFt: Bottom flange thickness }\end{array}$} \\
\hline
\end{tabular}


Table 3b. Reinforcement parameters of the specimens used in the numerical simulations at high temperature

\begin{tabular}{|c|c|c|c|c|c|c|c|}
\hline \multicolumn{8}{|c|}{ Reinforcement parameters } \\
\hline \multirow{2}{*}{ Source } & \multirow{2}{*}{ Id. } & \multicolumn{5}{|c|}{ Axis distance (mm) / Reinforcement } & \multirow{2}{*}{$\mathrm{A}_{\mathrm{p}}^{* 1}$} \\
\hline & & Row 1 & Row 2 & Row 3 & Row 4 & Row 5 & \\
\hline \multirow{4}{*}{$\begin{array}{c}\text { Aguado et al. } \\
\qquad[11]\end{array}$} & $\mathrm{HC} 25-\mathrm{A} 1$ & $22.5 / 12 \phi 5$ & $39.5 / 4 \phi 5$ & $56.5 / 2 \phi 5$ & $210.5 / 4 \phi 5$ & - & $432.0 \mathrm{~mm}^{2}$ \\
\hline & $\mathrm{HC} 25-\mathrm{A} 2$ & $22.5 / 4 \phi 9.3$ & $39.5 / 4 \phi 5$ & $56.5 / 2 \phi 5$ & $73.5 / 2 \phi 5$ & $210.5 / 4 \phi 5$ & $443.6 \mathrm{~mm}^{2}$ \\
\hline & $\mathrm{HC} 25-\mathrm{A} 3$ & $22.5 / 4 \phi 5$ & $39.5 / 4 \phi 9.3$ & $56.5 / 2 \phi 5$ & $73.5 / 2 \phi 5$ & $210.5 / 4 \phi 5$ & $443.6 \mathrm{~mm}^{2}$ \\
\hline & $\mathrm{HC} 25-\mathrm{A} 4$ & $39.5 / 4 \phi 9.3$ & $56.5 / 8 \phi 5$ & $210.5 / 4 \phi 5$ & - & - & $443.6 \mathrm{~mm}^{2}$ \\
\hline $\begin{array}{c}\text { Andersen and } \\
\text { Lauridsen } \\
{[31]}\end{array}$ & SP22 & $29.7 / 8 \phi 9.3$ & - & - & - & - & $416.0 \mathrm{~mm}^{2}$ \\
\hline \multirow{6}{*}{$\begin{array}{c}\text { Fellinger } \\
{[25]}\end{array}$} & A200 & $30 / 8 \phi 9.3$ & 165/4ф5 & - & - & - & $494.5 \mathrm{~mm}^{2}$ \\
\hline & X200 & $30 / 8 \phi 9.3$ & $165 / 4 \phi 5$ & - & - & - & $494.5 \mathrm{~mm}^{2}$ \\
\hline & XB200 & $45 / 8 \phi 9.3$ & $165 / 4 \phi 5$ & - & - & - & $494.5 \mathrm{~mm}^{2}$ \\
\hline & VX265 & $40 / 6 \phi 13$ & - & - & - & - & $600 \mathrm{~mm}^{2}$ \\
\hline & HVP260 & $40 / 6 \phi 13$ & $179 / 2 \phi 9.3$ & - & - & - & $704 \mathrm{~mm}^{2}$ \\
\hline & K400 & $40 / 8 \phi 13$ & $88 / 8 \phi 9.3$ & $360 / 2 \phi 6.9$ & - & - & $\begin{array}{c}1365.6 \\
\mathrm{~mm}^{2}\end{array}$ \\
\hline
\end{tabular}


Aguado JV, Albero V, Espinos A, Hospitaler A, Romero ML. A 3D finite element model for predicting the fire behavior of hollow-core slabs. Eng. Struct. 2016; 108C:12-27. doi:

Table 4. Comparison of numerical, test and simplified methods results at high temperature

\begin{tabular}{|c|c|c|c|c|c|c|c|c|c|c|c|c|c|}
\hline \multirow[b]{2}{*}{ Source } & \multirow[b]{2}{*}{ Id. } & \multirow[b]{2}{*}{ Test type } & \multirow[b]{2}{*}{$\eta$} & \multicolumn{2}{|c|}{ Test results } & \multicolumn{4}{|c|}{ Numerical Simulations } & \multicolumn{4}{|c|}{ Simplified Methods } \\
\hline & & & & $\begin{array}{c}\text { Failure } \\
\text { time (min) }\end{array}$ & $\begin{array}{l}\text { Failure } \\
\text { Mode }\end{array}$ & $\begin{array}{l}\text { Failure } \\
\text { time (min) }\end{array}$ & $\begin{array}{l}\text { Failure } \\
\text { Mode }\end{array}$ & $\begin{array}{c}\xi_{\mathrm{t}} \\
(\mathrm{Test} / \mathrm{NUM})\end{array}$ & $\begin{array}{c}\xi_{\mathrm{Vu}} \\
(\mathrm{Test} / \mathrm{NUM})\end{array}$ & $\begin{array}{l}\text { Failure } \\
\text { time 500IM } \\
\quad(\min )\end{array}$ & $\begin{array}{l}\text { Failure time } \\
\text { V-EN1168 } \\
(\min )\end{array}$ & $\begin{array}{l}\text { Failure } \\
\text { Mode }\end{array}$ & $\begin{array}{c}\xi_{\mathrm{t}} \\
(\mathrm{NUM} / \mathrm{Simp})\end{array}$ \\
\hline \multirow{4}{*}{$\begin{array}{l}\text { Aguado et al. } \\
\qquad[11]\end{array}$} & $\mathrm{HC} 25-\mathrm{A} 1$ & Four point & 0.36 & 84 & Flex. & 77 & Flex. & 1.09 & - & 64.0 & 130.4 & Flex. & 1.20 \\
\hline & $\mathrm{HC} 25-\mathrm{A} 2$ & Four point & 0.35 & 96 & Flex. & 88 & Flex. & 1.09 & - & 71.8 & 146.6 & Flex. & 1.23 \\
\hline & HC25-A3 & Four point & 0.36 & 105 & Flex. & 86 & Flex. & 1.22 & - & 91.9 & 150.2 & Flex. & 0.94 \\
\hline & HC25-A4 & Four point & 0.37 & 92 & Flex. & 81 & Flex. & 1.14 & - & 107.0 & 151.3 & Flex. & 0.76 \\
\hline $\begin{array}{c}\text { Andersen and } \\
\text { Lauridsen } \\
{[31]}\end{array}$ & SP22 & Four point & 1.00 & 26 & Shear & 24 & Shear & 1.08 & - & 47.3 & 51.0 & Flex. & 0.51 \\
\hline \multirow{3}{*}{$\begin{array}{c}\text { Fellinger } \\
{[25]}\end{array}$} & $\mathrm{X} 200$ & Shear test & 0.16 & 120 & Flex. & 120 & Flex. & - & 1.14 & 114.9 & 75.4 & Shear & - \\
\hline & VX265 & Shear test & 0.23 & 35 & Shear & 36 & Shear & 0.97 & - & 137.9 & $<30$ & Shear & - \\
\hline & XB200 & Shear test & 0.18 & 120 & Flex. & 120 & Flex. & - & 0.99 & 154.1 & 122.1 & Shear & - \\
\hline & & & & & & \multicolumn{2}{|c|}{ Average $\xi \mathrm{t}$} & 1.10 & & & \multicolumn{2}{|c|}{ Average $\xi \mathrm{t}$} & 0.93 \\
\hline & & & & & & \multicolumn{2}{|c|}{ Standard deviation } & 0.08 & & & \multicolumn{2}{|c|}{ Standard deviation } & 0.30 \\
\hline
\end{tabular}

